\title{
Trend and Variability of the Atmospheric Water Vapor: A Mean Sea Level Issue
}

\author{
SOULIVANH THAO \\ CLS, Ramonville Saint-Agne, France \\ LAURENCE EYMARD \\ LOCEAN/CNRS, Paris, France
}

ESTELle OBLiGis AND BRUNO PiCARD

CLS, Ramonville Saint-Agne, France

(Manuscript received 8 July 2013, in final form 19 February 2014)

\begin{abstract}
The wet tropospheric path delay is presently the main source of error in the estimation of the mean sea level by satellite altimetry. This correction on altimetric measurements, provided by a dedicated radiometer aboard the satellite, directly depends on the atmospheric water vapor content. Nowadays, water vapor products from microwave radiometers are rather consistent but important discrepancies remain. Understanding these differences can help improve the retrieval of water vapor and reduce at the same time the error on the mean sea level.

Three radiometers are compared: the Advanced Microwave Scanning Radiometer for Earth Observing System (AMSR-E), Jason-1 microwave radiometer (JMR), and Envisat microwave radiometer (MWR). Water vapor products are analyzed both in terms of spatial and temporal distribution over the period 2004-10, using AMSR-E as a reference. The Interim ECMWF Re-Analysis (ERA-Interim) data are also included in the study as an additional point of comparison. Overall, the study confirms the general good agreement between the radiometers: similar patterns are observed for the spatial distribution of water vapor and the correlation of the times series is better than 0.90. However, regional discrepancies are observed and a quantitative agreement on the trend is not obtained. Regional discrepancies are driven by the annual cycle. The JMR product shows discrepancies are highly dependent on water vapor, which might be related to calibration issues. Furthermore, triple collocation analysis suggests a possible drift of JMR. MWR discrepancies are located in coastal regions and follow a seasonal dynamic with stronger differences in summer. It may result from processing of the brightness temperatures.
\end{abstract}

\section{Introduction}

The ocean mean sea level (MSL) is a key indicator of the global warming. Its long-term survey is an issue not only for climate evolution study, but also for economic and social consequences of its elevation.

The mean sea level evolution is monitored and studied using tide gauge records, satellite altimetry measurements, and numerical models. Models are often combined with observations through assimilation techniques to

Corresponding author address: Soulivanh Thao, CLS, Spatial Oceanography, 8-10 rue Hermes, Ramonville Saint-Agne 31400, France.

E-mail: sthao@cls.fr improve the model outputs. Space observations play nowadays a major role in data assimilation. Indeed, satellites allow a nearly complete coverage of the ocean surface and data are provided in near-real time.

Exploitation of altimetry measurements over ocean depends on the feasibility of correcting the altimeter range for different perturbations. One of them, the wet tropospheric correction, is nearly proportional to the integrated water vapor and is provided by a dedicated instrument, a microwave radiometer, operating around the water vapor absorption line $(22 \mathrm{GHz})$.

The uncertainty in this correction is today a major part of the global mean sea level trend error budget. Any error in the wet path delay impacts directly the estimation of the sea level. Ablain et al. (2009) have estimated 
the wet path delay uncertainty at $0.3 \mathrm{~mm} \mathrm{yr}^{-1}$ over $1993-$ 2008 whereas the MSL trend has been estimated as $3.11 \mathrm{~mm} \mathrm{yr}^{-1}$ for the same period.

Most of the past and current radiometers on board altimetry missions have experienced drift problems, which are small compared to the natural variability of water vapor (interannual variations, seasonal cycle, and climate change). If uncorrected, theses drifts can affect the estimation of the long-term trend of water vapor. Moreover, the short lifespan of radiometers makes the observation of the water vapor evolution at a decadal time scale difficult. Thus, creating a homogenous, consistent, and representative product of water vapor for climatic studies remains a challenge.

Reanalyses tackle this problem by trying to optimally combine models outputs and different sources of measurements (satellite and in situ measurements) in order to provide "a multivariate, spatially complete and coherent record of the global and atmospheric circulations" (Dee et al. 2011). The consistency of the record is ensured by using a single and unique assimilation scheme for the whole period. Reanalyses are expected to be representative of global and regional variations of the atmosphere at diurnal, annual, interannual, and even decadal time scales to assess climate changes. Efforts are made to improve both the spatial and the temporal resolution of reanalyses. However, reanalyses are still affected by changes in the global observation system (e.g., change of instruments) and biases in the observations or the model. Therefore, knowledge of biases and drifts in the instruments included in the assimilation scheme is also essential.

Methods to detect and evaluate the drifts of radiometers are based on the long-term survey of the measured brightness temperatures over stable targets (cold ocean or specific continental areas) (Brown et al. 2009; Eymard et al. 2005), the comparison with measurements from other radiometers (Zlotnicki and Desai 2004), or the comparison with meteorological models [e.g., those of the European Centre for Medium-Range Weather Forecasts (ECMWF) and National Centers for Environmental Prediction (NCEP); Trenberth et al. 2005]. These analyses show many inconsistencies and bring out the necessity to understand them.

The comparison of different estimations is complicated because of inherent conception disparities: each mission has its own orbit, spatial and time resolution, processing, and editing. Therefore, methodological considerations to implement these comparisons are needed to avoid artifacts and biases in the results.

While the final aim of our study is to improve the wet tropospheric path delay for the long-term survey of the mean sea level, this paper focuses on the atmospheric water vapor. Indeed, it is the main component of the wet tropospheric path delay and its main source of variation. Moreover, water vapor in itself is a key indicator of climate change as it is the most abundant greenhouse gas on Earth. Recent studies show that water vapor has increased in the last decades, although not homogenously over the ocean. Keihm et al. (2009) have estimated the global integrated water vapor trend at $0.0055 \pm$ $0.0012 \mathrm{~g} \mathrm{~cm}^{-2} \mathrm{yr}^{-1}$ for the period 1992-2005 using Ocean Topography Experiment (TOPEX) microwave radiometer data. Trenberth et al. (2005) also found a positive water vapor trend of $0.0040 \pm 0.0009 \mathrm{~g} \mathrm{~cm}^{-2} \mathrm{yr}^{-1}$ between 1988 and 2003 using the Special Sensor Microwave Imager (SSM/I) measurements.

The objective of our study is to assess the consistency of current radiometer products of water vapor at the global and regional scale but also at different time scales (annual, interannual, and long-term trend). The characterization of the discrepancies may help to distinguish natural variations of water vapor from systematic instrumental or algorithmic anomalies. Understanding where and when anomalies occur will help to pinpoint their causes. Such evaluations are necessary to identify areas where potential errors remain and to propose adequate corrections.

To do so, we chose to compare three radiometer products of water vapor between 2004 and 2010 from the Advanced Microwave Scanning Radiometer for Earth Observing System (AMSR-E), the Jason-1 microwave radiometer (JMR), and the Envisat microwave radiometer (MWR). These three radiometers allow the comparison of three independently built datasets: the radiometers have different architecture and each product was built using a different retrieval algorithm and different editing criteria. JMR and MWR are radiometers on board altimetry missions whereas AMSR-E is specifically built to study Earth's water cycle. The latter has been intercalibrated by Remote Sensing Systems (RSS) with the Special Sensor Microwave Imager and the Special Sensor Microwave Imager/Sounder (SSM/IS) radiometer aboard Defense Meteorological Satellite Program (DMSP) satellites (Wentz et al. 2003). Measurements from SSM/I and SSM/IS form the longest record of water vapor of the satellite era: reprocessed and homogeneous datasets are available since 1987. Hence, it represents one of the most elaborate records of water vapor (Trenberth et al. 2005). For these reasons, the AMSR-E water vapor product is used as a reference in our study.

At first, the analyses were also performed with SSM/IS DMSP F-16 (F-16), which was launched in October 2003. It was, however, decided not to include SSM/I radiometers in this paper. Indeed, it was chosen to only include 
radiometer products that have been processed independently. Comparing related products could lead to biases in the interpretation of the results, especially as the detection of anomalies is based on comparisons in this study. Our analyses indeed revealed that the agreement between AMSR-E and SSM/IS F-16 water vapor products is very good: in our study, AMSR-E and SSM/IS F-16 could almost have been used interchangeably. However, we assume that the good agreement is likely due to their intercalibration. Thus, introducing SSM/IS F-16 as well AMSR-E in the comparison would have been redundant.

The Interim ECMWF Re-Analysis (ERA-Interim) will be used as an additional point of comparison. ERAInterim is the latest global atmospheric reanalysis project from the ECMWF (Dee et al. 2011). The project aims, among other things, at providing a homogeneous and consistent record of water vapor since 1989 and is widely used in climate research community. AMSR-E brightness temperatures over ocean are assimilated in the ERA-Interim reanalysis; the two datasets are therefore not independent.

Section 2 presents the relationship between water vapor and wet tropospheric path delay, the instruments used, and the radiometer datasets. The results of the analyses are divided into two parts. Section 3 is dedicated to the relative errors. Analyses from global and constant biases to dynamic and regional discrepancies are presented: the observed differences are analyzed in terms of intensity, spatial distribution, temporal trends, and variability patterns. Section 4 concerns the estimation of the error standard deviation of each mission using the methodology called triple collocation. Section 5 is dedicated to interpretation and discussions of the results. Finally, the last section offers the conclusions and the perspectives of this study.

\section{Water vapor, instruments, and datasets}

\section{a. Relationship between the integrated water vapor content and the wet tropospheric path delay}

The wet tropospheric correction in altimetry is required to correct the altimeter range from the additional delay due to water vapor molecules in the troposphere. Therefore, the integrated water vapor content and the wet tropospheric path delay are highly correlated. Their relationship is almost linear (Fig. 1). However, they are not equivalent physical quantities as the wet tropospheric path delay also depends on temperature, pressure, and humidity profiles of the atmosphere (Fu and Cazenave 2000):

$$
d h=K \int \frac{\rho(z)}{T(z)} d z
$$

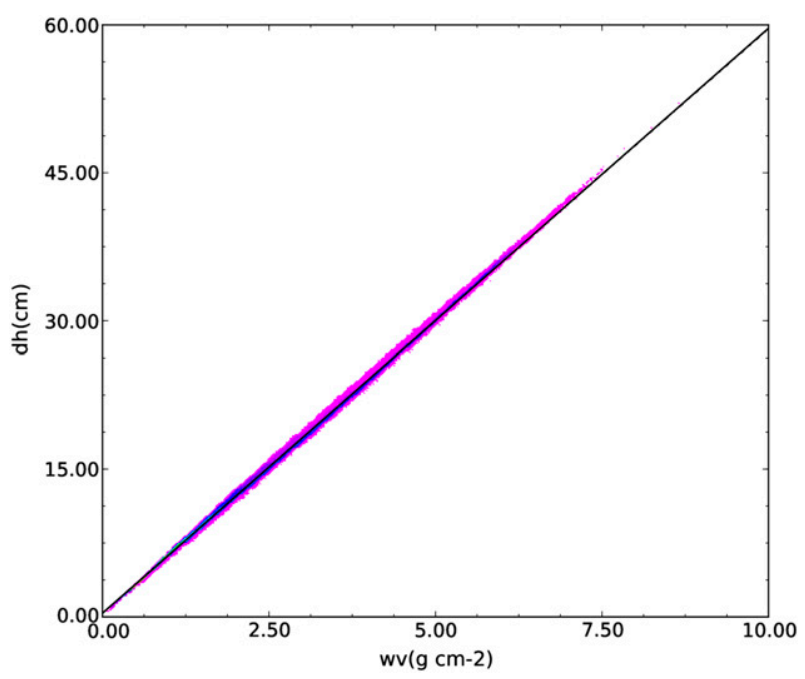

FIG. 1. Scatterplot of wet tropospheric path delay $(\mathrm{cm})$ vs integrated water vapor content $\left(\mathrm{g} \mathrm{cm}^{-2}\right)$. Original atmospheric profiles come from ECMWF analyses from 2008 and 2009.

where $d h$ is the wet tropospheric path delay $(\mathrm{cm}), \rho(z)$ is the density of water vapor at the altitude $z\left(\mathrm{~g} \mathrm{~cm}^{-3}\right)$, $T(z)$ is the temperature at the altitude $z$, and $K$ is a constant equal to $1720.6 \mathrm{~K} \mathrm{~cm}^{3} \mathrm{~g}^{-1}$.

Zlotnicki and Desai (2004) took advantage of the strong relationship between the water vapor content and the wet tropospheric path delay to assess the wet tropospheric path delay of JMR using water vapor measurements from SSM/I and Tropical Rainfall Measuring Mission (TRMM) Microwave Imager (TMI). A polynomial transfer function was used to convert water vapor into wet tropospheric path delay. The relationship given by the transfer function is, however, not perfect as geographically correlated residual errors remain.

Since the wet tropospheric path delay is not available in the AMSR-E products from RSS, the original water vapor products from the three radiometers are directly compared to avoid introducing additional errors through the use of a transfer function. The following first-order approximation (Fu and Cazenave 2000) is used in this paper to have a rough idea of how water vapor impacts measurements of the sea level through the wet tropospheric path delay:

$$
d h=6.4(\mathrm{wv}),
$$

with $d h(\mathrm{~cm})$ and wv $\left(\mathrm{g} \mathrm{cm}^{-2}\right)$. This relationship is notably used to translate water vapor trends into wet tropospheric path delay trends. The approximation might differ from the relation seen in Fig. 1. Figure 1 has been computed from ECMWF profiles from 2008 and 2009: analyses are taken for the first of each month at 1200 UTC. 
TABLE 1. Nominal characteristics of the studied radiometers and their mission.

\begin{tabular}{|c|c|c|c|}
\hline Mission & Jason-1 & Aqua & Envisat \\
\hline Life in space & Dec 2001-Jul 2013 & May 2002-present & Mar 2002-Apr 2012 \\
\hline \multirow{5}{*}{$\begin{array}{l}\text { Radiometer name channels }(\mathrm{GHz}) \\
\text { spatial resolution }(\mathrm{km})\end{array}$} & JMR & AMSR-E & MWR \\
\hline & 18.7 & $6.9(\mathrm{~V} / \mathrm{H}), 10.7(\mathrm{~V} / \mathrm{H})$ & 23.8 \\
\hline & 23.8 & $18.7(\mathrm{~V} / \mathrm{H}), 23.8(\mathrm{~V} / \mathrm{H})$ & 36.5 \\
\hline & 34 & $36.5(\mathrm{~V} / \mathrm{H}), 89.0(\mathrm{~V} / \mathrm{H})$ & 20 \\
\hline & 41.6 & 21 & \\
\hline \multirow[t]{4}{*}{ Orbit inclination cycle altitude } & & Sun-synchronous circular & Sun-synchronous \\
\hline & $62^{\circ}$ & $98.14^{\circ}$ & $98.6^{\circ}$ \\
\hline & 10 days & 16 days & 35 days \\
\hline & 1336 & $705 \mathrm{~km}$ & $799 \mathrm{~km}$ \\
\hline
\end{tabular}

\section{b. Radiometer and mission characteristics}

Main and nominal characteristics of the radiometers and their mission are summarized in Table 1. A change of orbit occurred for Envisat in October 2010. The extension orbit had a new altitude of $782 \mathrm{~km}$. In the extension orbit only the altitude is monitored, meaning that the inclination may be drifting. In April 2012, Jason-1 was put in a drifting geodetic orbit at $1324.0 \mathrm{~km}$ following the anomaly at the end of February 2012 and early in March 2012, where Jason-1 was in "safe hold" mode. AMSR-E stopped providing data since August 2011 due to the rotating mechanism of the radiometer being damaged.

Only data from 2004 to 2010 are considered in this paper. This corresponds to the period when all radiometers (including SSM/IS F-16) were in function. The study also stops in 2010 to minimize the effects of orbits changes. Full years were used to minimize annual effects on the estimation of the water vapor trends.

AMSR-E data that we used are produced by Remote Sensing Systems and are provided in daily ascending and descending orbit grids with a resolution of $0.25^{\circ}$. The version v.07 of the reprocessed data is used. Envisat and Jason-1 datasets of water vapor take form of level 2, $1-\mathrm{Hz}$ along-track products. Jason-1 data used are from the Geophysical Data Record (GDR). In this study, GDR version $\mathrm{c}$ is used as it forms a homogeneous dataset over the period 2004-10 for Jason-1. Envisat data used are from the GDR. In this study, the reprocessed version of the data (V2.1) is used. Data from cycles 9 to 92 (from 2002 to 2011) were reprocessed into a homogeneous standard. ERA-Interim data are produced by ECMWF, which provides daily fields at 0000, 6000, 1200, and 1800 UTC at a resolution of $0.75^{\circ}$.

The differences in the format of different data reflect the discrepancies in the spatiotemporal sampling of the radiometers. While the orbits of AMSR-E and Envisat are similar, the architecture of the radiometers differs. The radiometers of Jason-1 and Envisat are nadir-viewing radiometers whereas AMSR-E observes Earth with a conical-scanning mechanism allowing a rotation of the sensor over an azimuth angle of $132^{\circ}$. In one scan, the measurements, made with an incidence angle of $55^{\circ}$, cover a swath width of $1400 \mathrm{~km}$. A nearly complete coverage of the surface of Earth is achieved in 2 or 3 days.

AMSR-E has more channels than JMR and MWR. AMSR-E is a dual-polarized radiometer whose measurements of brightness temperature are made at the following frequencies: $6.9,10.7,18.7,23.8,36.5$, and $89.0 \mathrm{GHz}$. However, only the 18.7-, 23.8-, and 36.5-GHz brightness temperatures are used in the water vapor retrieval algorithm (Wentz and Meissner 2007). JMR measurements are also performed at $18.7,23.8$, and $34 \mathrm{GHz}$ (Keihm et al. 1995). MWR has only two channels, at 23.8 and $36.5 \mathrm{GHz}$. Information on the sea surface roughness, usually given by a low-frequency channel, is provided by the Ku-band backscattering coefficient of the RA-2 altimeter, aboard Envisat (Obligis et al. 2006).

Each mission uses a semistatistical algorithm to retrieve the water vapor content and/or the wet tropospheric path delay from the brightness temperatures. Nevertheless, the statistical regression methods are different, as well as the learning databases.

For AMSR-E, the water vapor is retrieved using a twostep log-linear model, built on a global database consisting of radiosonde measurements (Wentz and Meissner 2007). As AMSR-E is used as the common reference, the choice has been done to perform the comparisons between water vapor products instead of the wet tropospheric path delay.

For JMR, a two-step log-linear model built on a radiosonde database is also used but to retrieve the wet tropospheric path delay (Keihm et al. 1995). The integrated water vapor content provided in the product is then deduced using an empirical relationship between the wet tropospheric path delay and the integrated water vapor.

For MWR, a neural network regression applied on a global database consisting of ECMWF analyses is used and allows a direct retrieval of the water vapor from the 
brightness temperatures. Details of the neural network architecture used are provided in Obligis et al. (2006).

The differences between missions in terms of spatial and temporal sampling, radiometer architecture, or data processing methods could lead to static or time-varying biases among the water vapor products. The differences are essential information in order to detect instrumental drifts from natural differences through mission intercomparisons.

\section{c. Harmonization of the data}

To use a common format for the datasets, each dataset is put into monthly grids between $\pm 66^{\circ}$ of latitude with a resolution of $3^{\circ}$. The choice of this spatial and temporal resolution is a compromise between the highest possible resolution and a sufficient number of measurements per bin to provide a good statistical estimation of parameters, such as mean or standard deviation. For each dataset, only measurements validated by their respective processing teams are kept. Moreover, bins are rejected from the study if for a given month less than 50 measurements are present in either one of the AMSR-E, JMR, or MWR corresponding bins. Therefore, the number of valid bins remains constant at each time and for each mission. For the data from JMR and MWR, we only kept measurements whose distance to the coast is higher than $100 \mathrm{~km}$ to avoid the contamination of brightness temperatures by land. For ERA-Interim, the daily grids of water vapor at $0000,6000,1200$, and 1800 UTC are averaged into monthly grids with a resolution of $3^{\circ}$. As for the radiometer, only bins also present in the radiometer grids are kept. In the following, we will consider one bin of monthly grids as the smallest unit of comparison. Therefore, variations with temporal scales smaller than a month are not considered.

The comparison of water vapor products from radiometers usually relies on the determination of the differences at crossover points or match-ups. The use of match-ups is justified by the high variability of water vapor. When match-ups are used, the noise of the differences between radiometers is minimized since both radiometers observe the same scene under the same conditions. But in this case, only a low fraction of satellite data is used, and the number of match-ups can be low, and with a critical geographical distribution, depending on the geometry of the satellite orbits. For instance, the use of match-ups cannot be considered for the comparison of AMSR-E and MWR since there are very few match-ups between the two missions. The repartition of bins containing at least one match-up between AMSR-E and JMR is given in Fig. 2. The evolution of the number of bins with match-ups with respect to latitude and time is not uniform. For latitudes between $40^{\circ} \mathrm{N}$ and $40^{\circ} \mathrm{S}$,

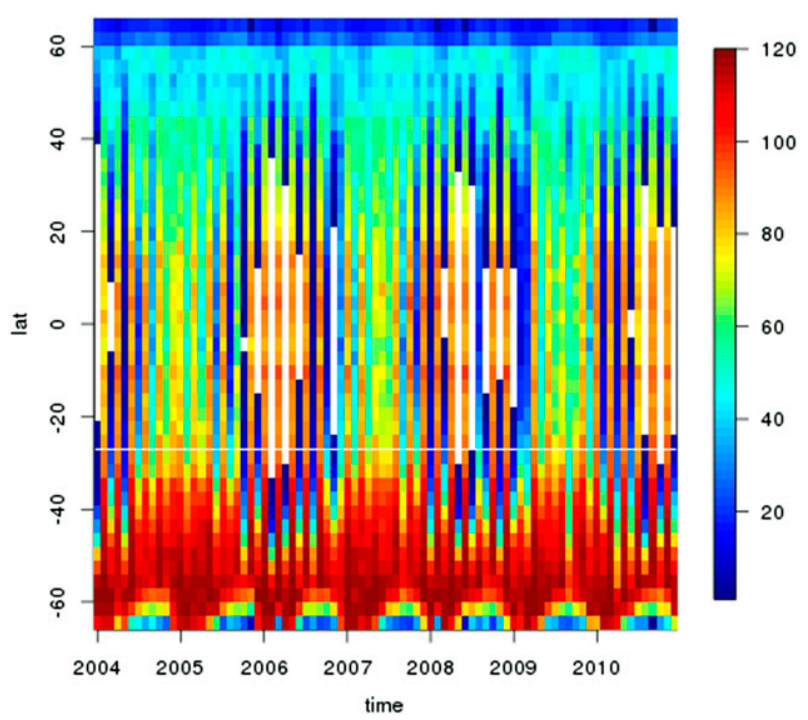

FIG. 2. Hovmöller diagrams of number of bins with at least one match-up between AMSR-E and JMR.

there is a gap in the data with very few crossovers about every two years. In this case, we consider that the analysis of match-ups will lack representativeness of the space and time dynamics of discrepancies.

\section{Relative errors}

In this section, relative errors of the MWR and JMR radiometers and the ERA-Interim reanalysis, with respect to AMSR-E, are studied. The differences are analyzed from static and global biases to local and dynamic discrepancies.

\section{a. Spatial distribution of water vapor}

In this section, the geographical averaged distribution of water vapor is analyzed. Monthly maps of water vapor are averaged between 2004 and 2010 (Fig. 3). Those maps show that water vapor is mainly structured according to latitude, with stronger values near the equator. Global statistics for the three radiometers and the reanalysis are close (Table 2). They indicate a global bias of $0.12(0.13) \mathrm{g} \mathrm{cm}^{-2}$ between AMSR-E products and JMR (MWR) products. ERA-Interim shows higher values in average than the radiometers with a bias of $0.06 \mathrm{~g} \mathrm{~cm}^{-2}$ with AMSR-E. The variance of the four maps of averaged water vapor is very close. Maxima of the differences reach $0.37 \mathrm{~g} \mathrm{~cm}^{-2}$. It represents a maximum difference of about $2.37 \mathrm{~cm}$ in terms of wet tropospheric path delay.

JMR and MWR globally underestimate the water vapor content with respect to AMSR-E, whereas ERAInterim overestimates the water vapor content compared to the radiometers (Fig. 4). 


\section{Average of water vapor $\left(\mathrm{g} \mathrm{cm}^{-2}\right)$ between 2004 and 2010}

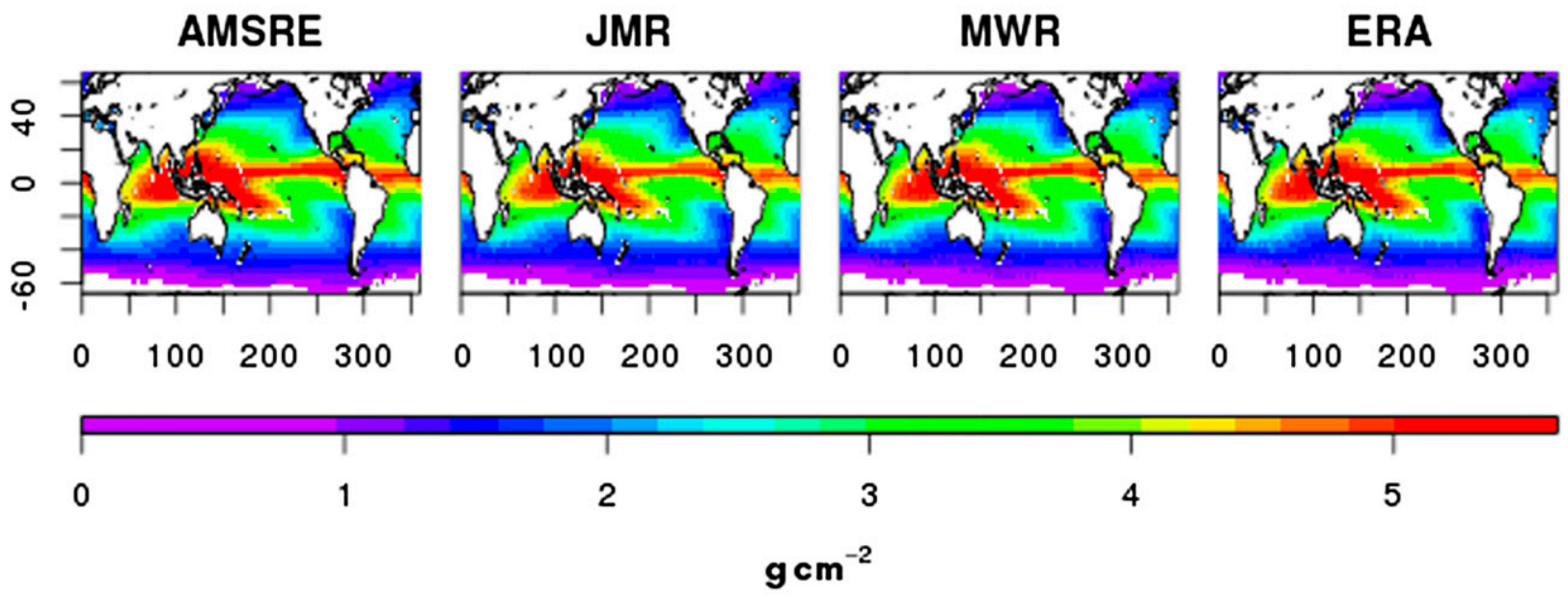

Difference of average of water vapor $\left(\mathrm{g} \mathrm{cm}^{-2}\right)$ between 2004 and 2010

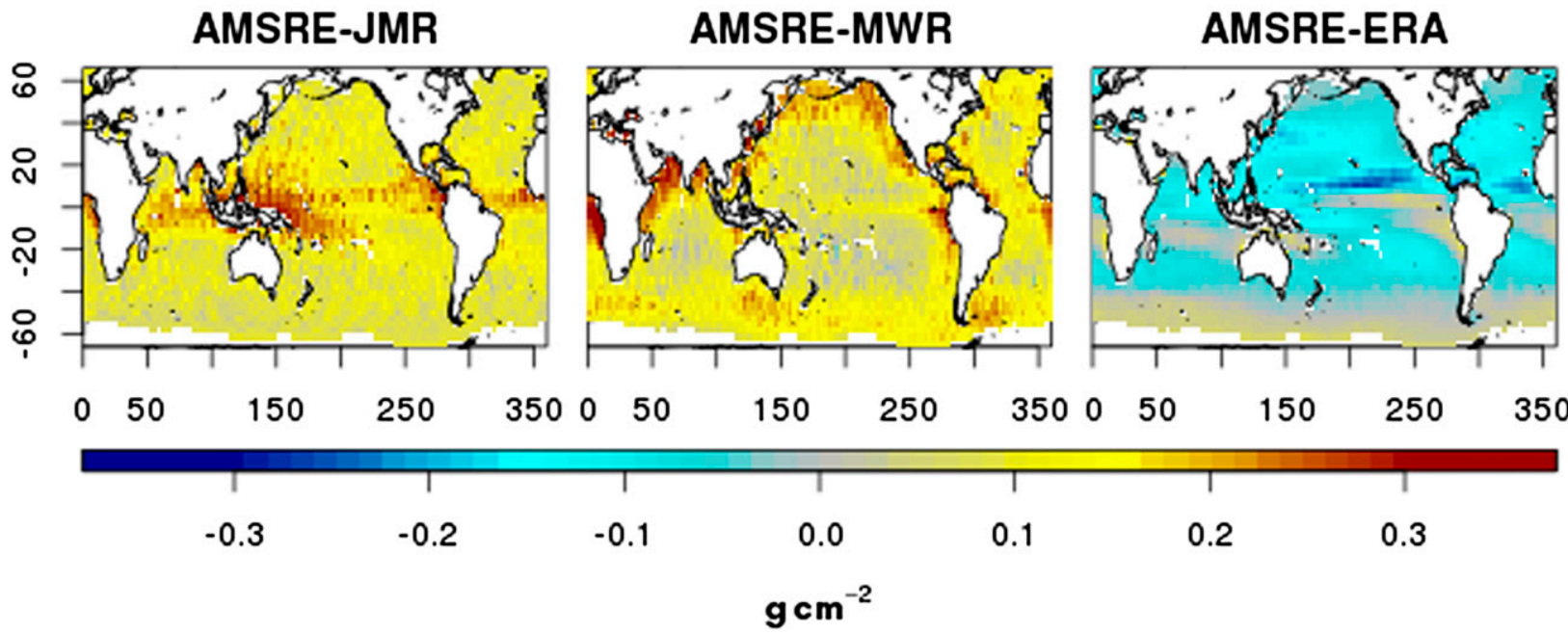

FIG. 3. Averaged maps of (top) water vapor $\left(\mathrm{g} \mathrm{cm}^{-2}\right)$ between 2004 and 2010 and (bottom) the differences of water vapor $\left(\mathrm{g} \mathrm{cm}^{-2}\right)$ between 2004 and 2010.

- For JMR, the differences increase with the water content. It explains why the discrepancies have the same structures as water vapor itself and why the largest differences are located in the tropics.

- For MWR, the largest differences concern coastal regions of the Northern Hemisphere and upwelling areas. The most important differences appear for water vapor content around $1 \mathrm{~g} \mathrm{~cm}^{-2}$. A second peak, although less important, is present for water vapor value around $4 \mathrm{~g} \mathrm{~cm}^{-2}$.

- For ERA-Interim, the water vapor is globally overestimated with respect to AMSR-E, especially in the tropics in the Atlantic and Pacific Oceans. However, the water vapor is underestimated in high latitudes of the Southern Hemisphere and in the coasts of Peru and Angola. The scatterplot shows a strong dependence of the discrepancies with water vapor up to $2 \mathrm{~g} \mathrm{~cm}^{-2}$.

The three radiometers and ERA-Interim are consistent on the global scale but exhibit geographically correlated discrepancies at the regional scale. However, does the relative behavior between the radiometers remain stable over time and how do the regional discrepancies evolve with time? In the next part, analysis of time series is performed to check whether the three radiometers record the same temporal trend of the water vapor. 
TABLE 2. Statistics of water vapor bins composing the averaged maps of water vapor between 2004 and 2010.

\begin{tabular}{lcccccrr}
\hline & AMSR-E & JMR & MWR & ERA-Interim & AMSR-E -JMR & AMSR-E -MWR & AMSR-E - ERA-Interim \\
\hline$\mu\left(\mathrm{g} \mathrm{cm}^{-2}\right)$ & 2.70 & 2.58 & 2.57 & 2.76 & 0.12 & 0.13 & -0.06 \\
$\sigma\left(\mathrm{g} \mathrm{cm}^{-2}\right)$ & 1.32 & 1.28 & 1.33 & 1.36 & 0.05 & 0.06 & 0.06 \\
$\operatorname{Min}\left(\mathrm{g} \mathrm{cm}^{-2}\right)$ & 0.75 & 0.66 & 0.66 & 0.68 & -0.0 & -0.04 & -0.26 \\
$\operatorname{Max}\left(\mathrm{g} \mathrm{cm}^{-2}\right)$ & 5.57 & 5.34 & 5.62 & 5.77 & 0.31 & 0.37 & 0.18 \\
\hline
\end{tabular}

\section{b. Water vapor trends}

The aim of this part is to determine whether the three radiometers observe the same evolution of water vapor over time: do all radiometers qualitatively show an increase (or a decrease) of the tropospheric water vapor between 2004 and 2010? To answer that question, statistical models are used to assess whether the total amount of water vapor has significantly changed. For each dataset, a monthly time series of water vapor is built by averaging every bin of $3^{\circ}$ from the same month. Then, the following time series decomposition is applied to model the evolution of the average water vapor content through time:

$$
\mathrm{wv}_{r, t}=U_{r}+T_{r, t}+S_{r, t}+R_{r, t},
$$

where $\mathrm{wv}_{r, t}$ is the atmospheric water vapor at time $t$ measured by the radiometer $r, U_{r}$ is the mean of the water vapor content from 2004 to $2010, T_{r, t}$ is the trend, $S_{r, t}$ is the annual seasonality, and $R_{r, t}$ are the residuals. The trend represents the long-term behavior of the time series. From a signal processing point of view, it would correspond to the signal removed of its high frequencies. The seasonality corresponds to periodic variation of the signal. In our case, we choose a cycle of 12 months as we know that the annual cycle of water vapor is one of its main sources of variation. The residuals are composed of phenomena unexplained by the model. Thus, they are modeled as a random process. Generally, residuals are small and present irregular variations. It is often referred as the noise of the signal.

The trend of water vapor does not depend on the average value of water vapor but only on the temporal variations of water vapor. Thus, each time series is centered. We call "anomalies" the time series with their respective mean removed:

$$
A_{r, t}=\mathrm{wv}_{r, t}-U_{r}=T_{r, t}+S_{r, t}+R_{r, t} .
$$

Time series of the anomalies of water vapor are shown in the top panel of Fig. 5. Correlation between AMSR-E and MWR time series is equal to 0.94 and correlation between AMSR-E and JMR is equal to 0.90. The correlation between AMSR-E and ERA-Interim time series is 0.96, better than the correlation between AMSR-E and MWR or JMR. Thus, the evolution of water vapor seen by the three radiometers and the reanalysis looks consistent. However, the three time series are not perfectly correlated: differences in amplitude are present and the JMR time series contains higher frequencies, for instance.

\section{Scatterplot of differences of average water vapor with respect to AMSRE}
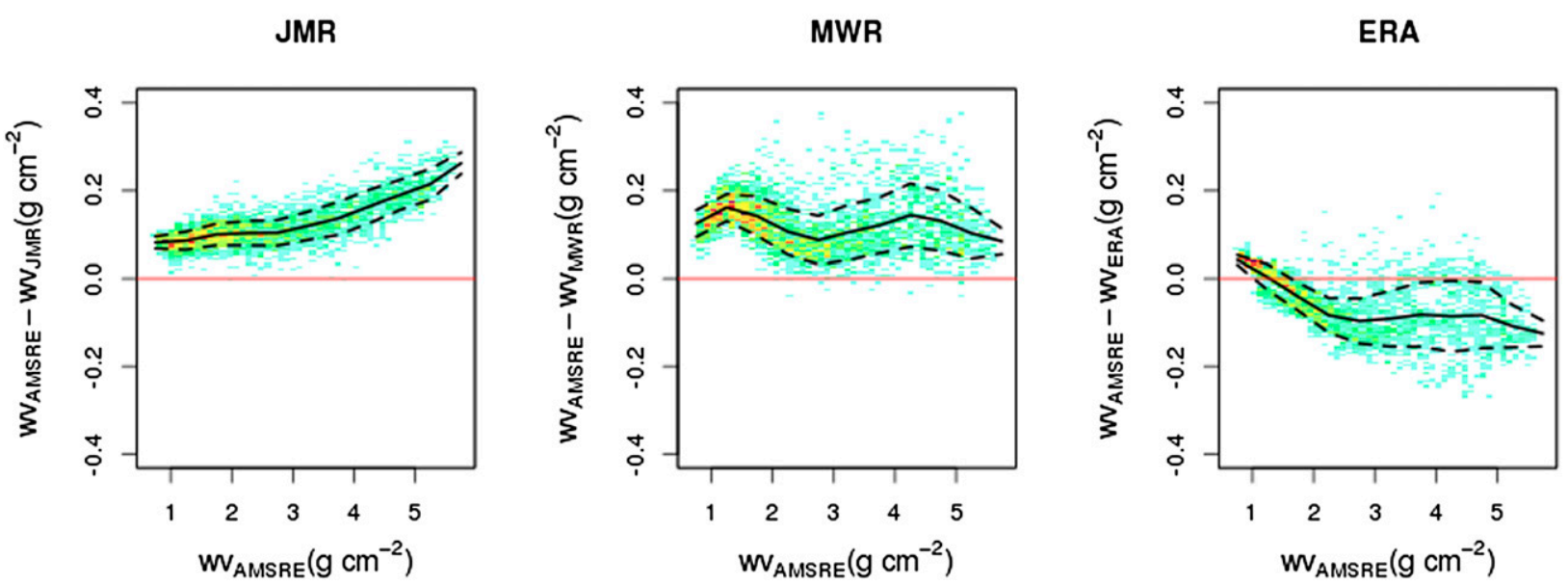

FIG. 4. Scatterplots of differences of water vapor $\left(\mathrm{g} \mathrm{cm}^{-2}\right)$ with respect to water vapor from AMSR-E $\left(\mathrm{g} \mathrm{cm}^{-2}\right)$. 
Time Serie

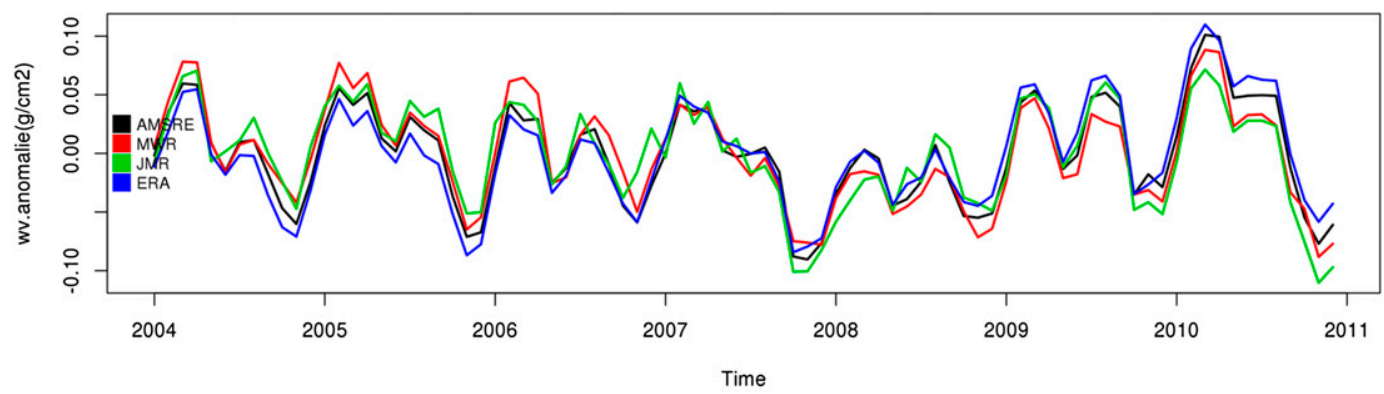

Time Serie : AMSRE-XXX

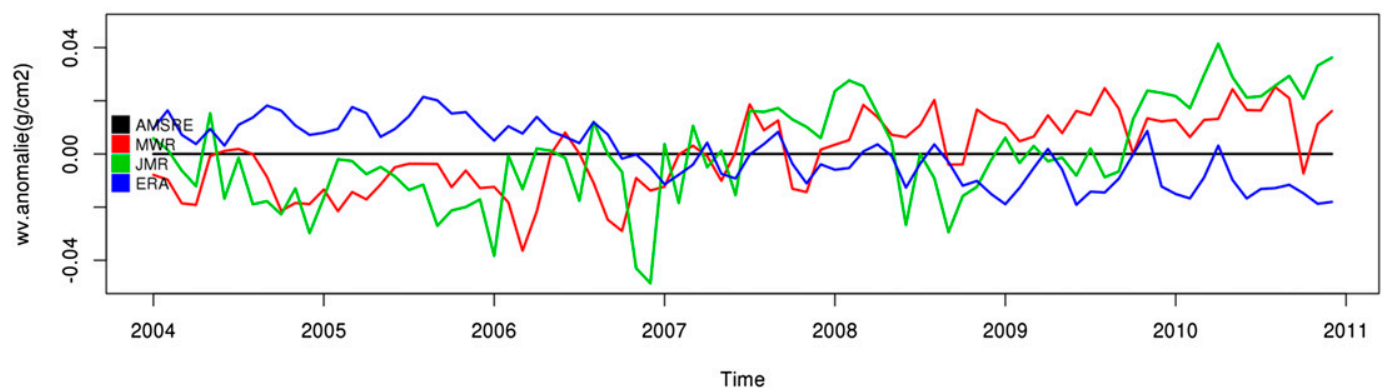

FIG. 5. (top) Time series of water vapor anomalies and (bottom) time series of differences of water vapor anomalies $\left(\mathrm{g} \mathrm{cm}^{-2}\right)$.

The trend component $\left(T_{r, t}\right)$ is modeled by a linear trend:

$$
T_{r, t}=m_{r} \times t+b_{r}
$$

where $t$ is the time, $m_{r}$ is the slope of the trend, and $b_{r}$ is the $y$ intercept; $m_{r}$ and $b_{r}$ are coefficients to be determined. Note that $T_{r, t}$ is commonly computed by ordinary least squares. If $m$ is significantly different from 0 , then we can conclude an increase or a decrease of the amount of water vapor.

The annual seasonality $\left(S_{r, t}\right)$ is computed as the average of water vapor for every same month. For instance, the seasonal component for January is estimated by averaging every measurements of water vapor made in January.

Using the model defined from (4) and (5), the decomposition in trend, seasonality, and residuals of the anomalies time series is shown in Fig. 6 for AMSR-E. The estimation of the seasonality shows two major modes. They correspond to the alternation of summers between Earth's Northern and Southern Hemispheres. These two modes are also seen on the seasonal component of the three other products of water vapor.

To test the significance of the parameters of the model, it is required to characterize the law of the residuals. The classical assumption of independent and identically distributed (i.i.d.) Gaussian variables is not made here as the residuals show signs of positive autocorrelation (Fig. 6). The analysis of the correlogram and the partial correlogram (not shown here), for all water vapor products, indicates that the residuals can be modeled by a stationary autoregressive process of order 1 .

All parameters of the model are computed at the same time by generalized least squares to take into account the correlation structure between the observations. The estimations of trends from the different datasets of water vapor as well as the test of nullity of the trend are given in Table 3. The estimated trends for JMR and MWR are negative, whereas for AMSR-E the trend is slightly positive. ERA-Interim shows a positive trend much higher than those measured by the radiometers. However, none of the observed trends is significantly different from 0 for a level of significance $\alpha=0.05$. Therefore, it is not possible to reject the hypothesis that the amount of water vapor remained stable from 2004 to 2010.

Although we cannot conclude to significant trends of water vapor, the question remaining is whether the AMSR-E, JMR, MWR, and ERA trends are statistically different from each other. Thus, we now work with the times series of differences of water vapor (Fig. 5, bottom panel).

The time series of differences are modeled following (4). For the time series of differences between AMSR-E 


\section{AMSRE}
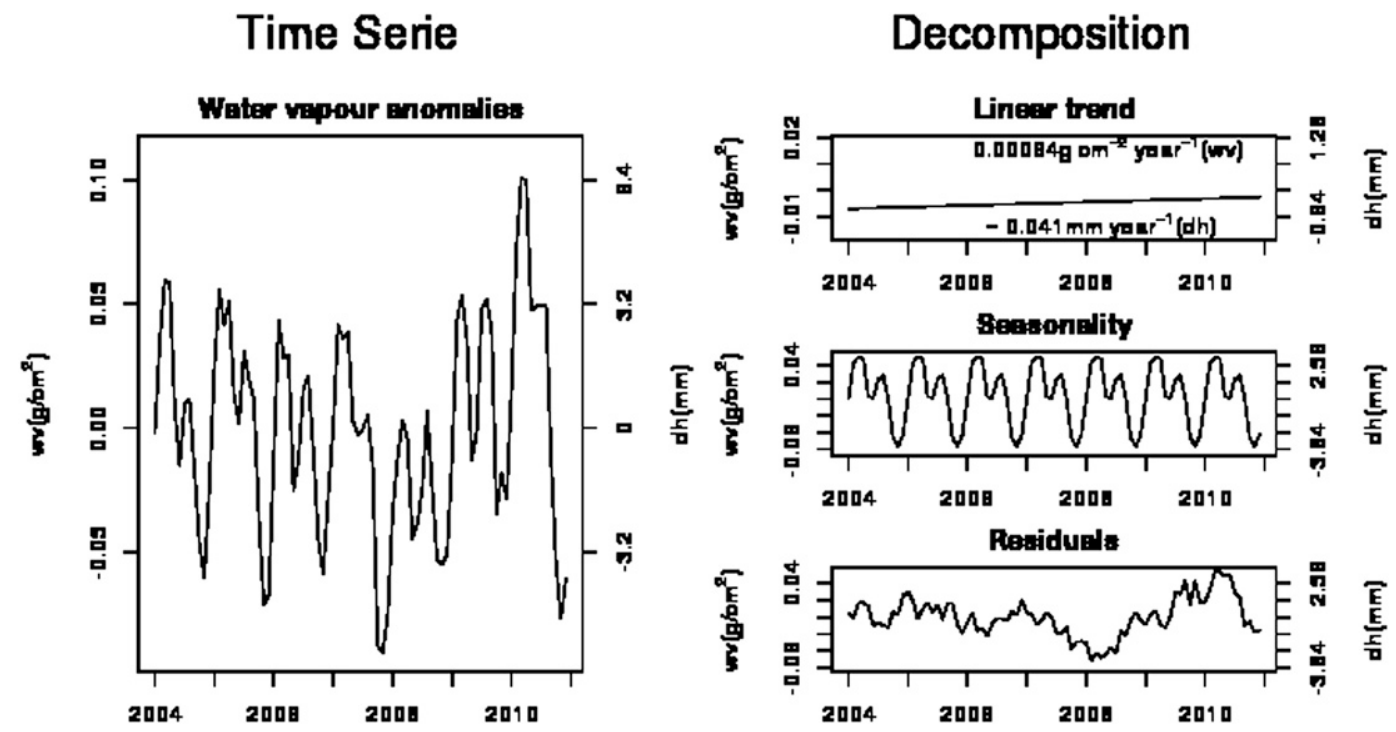

FIG. 6. (left) AMSR-E times series of anomalies and (right) its decomposition in trend $T$, seasonality $S$, and residuals $R\left(\mathrm{~g} \mathrm{~cm}^{-2}\right)$.

and JMR, the analysis of the correlogram and the partial correlogram of the residuals indicate that they can be modeled by a stationary autoregressive process of order 2. In the case of the differences between AMSR-E and MWR or between AMSR-E and ERA-Interim, for the AMRE-E-MWR or the AMSR-E-ERA-Interim time series, the seasonal component $\left(S_{r, t}\right)$ was not found significant (i.e., the differences do not exhibit an annual cycle). Thus, for those time series, the seasonal component $\left(S_{r, t}\right)$ was removed from the model. The time series are only decomposed in two components: a trend $\left(T_{r, t}\right)$ and the residuals. The residuals are modeled by a stationary first-order moving average process according to the analysis of the residuals.

The trend of the differences between AMSR-E and JMR (or MWR or ERA-Interim) is statistically significant
(Table 3). While the statistical model cannot confirm change in the amount of water vapor between 2004 and 2010 , the radiometers show significant differences in trends. Differences between the radiometers and the reanalysis have also significantly increased over the period 2004-10. As a comparison, we used the same type of model to estimate the trend of the differences between SSM/IS F-16 and AMSR-E radiometers, which are intercalibrated. The trend estimated at $-0.36 \times$ $10^{-3} \mathrm{~g} \mathrm{~cm}^{-2} \mathrm{yr}^{-1}$ was not significant $(\alpha=0.05)$.

It should be noted that all statistical tests for trends in this paper have been realized with a significance level of $\alpha=0.05$. It means that, under the assumption of the model, when a trend has been determined statistically significant, there is $5 \%$ of chance that our conclusion is wrong due to the stochastic nature of the model.

TABLE 3. Test of nullity of the trend of water vapor content measured by each mission and test of nullity for the trend of differences between missions. The tests are made using knowing that the estimators are asymptotically normal. The $t$ value is the computed value of the test statistics. The $p$ value indicates the percentage of chance to be wrong (under the assumptions of the models) when concluding to a significant change in the water vapor content level in this period.

\begin{tabular}{lrcrcc}
\hline \hline \multicolumn{1}{c}{ Mission } & $\begin{array}{c}\text { Estimation } \\
\left(\mathrm{g} \mathrm{cm}^{-2} \mathrm{yr}^{-1}\right)\end{array}$ & $\begin{array}{c}\text { Std error } \\
\left(\mathrm{g} \mathrm{cm}^{-2} \mathrm{yr}^{-1}\right)\end{array}$ & $t$ value & $p$ value & $\begin{array}{c}\text { IC_0.95 } \\
\left(\mathrm{g} \mathrm{cm}^{-2} \mathrm{yr}^{-1}\right)\end{array}$ \\
\hline AMSR-E & $0.64 \times 10^{-3}$ & $4.11 \times 10^{-3}$ & 0.154 & 0.878 & {$\left[-7.46 \times 10^{-3} ; 8.74 \times 10^{-3}\right]$} \\
MWR & $-3.78 \times 10^{-3}$ & $4.08 \times 10^{-3}$ & -0.927 & 0.357 & {$\left[-11.8 \times 10^{-3} ; 4.22 \times 10^{-3}\right]$} \\
JMR & $-4.43 \times 10^{-3}$ & $3.96 \times 10^{-3}$ & -1.118 & 0.267 & {$\left[-12.1 .9 \times 10^{-3} ; 3.33 \times 10^{-3}\right]$} \\
ERA & $5.21 \times 10^{-3}$ & $3.97 \times 10^{-3}$ & 1.311 & 0.194 & {$\left[-2.57 \times 10^{-3} ; 12.9 \times 10^{-3}\right]$} \\
AMSR-E-MWR & $4.90 \times 10^{-3}$ & $0.70 \times 10^{-3}$ & 6.961 & 0 & {$\left[3.53 \times 10^{-3} ; 6.27 \times 10^{-3}\right]$} \\
AMSR-E-JMR & $5.66 \times 10^{-3}$ & $2.08 \times 10^{-3}$ & 2.717 & 0.008 & {$\left[1.58 \times 10^{-3} ; 9.74 \times 10^{-3}\right]$} \\
AMSR-E-ERA & $-4.34 \times 10^{-3}$ & $0.46 \times 10^{-3}$ & -9.156 & 0 & {$\left[-5.24 \times 10^{-3} ;-3.444 \times 10^{-3}\right]$} \\
\hline
\end{tabular}


Non-Linear Trends of water vapor monthly anomalies and 95\% Confidence Intervals
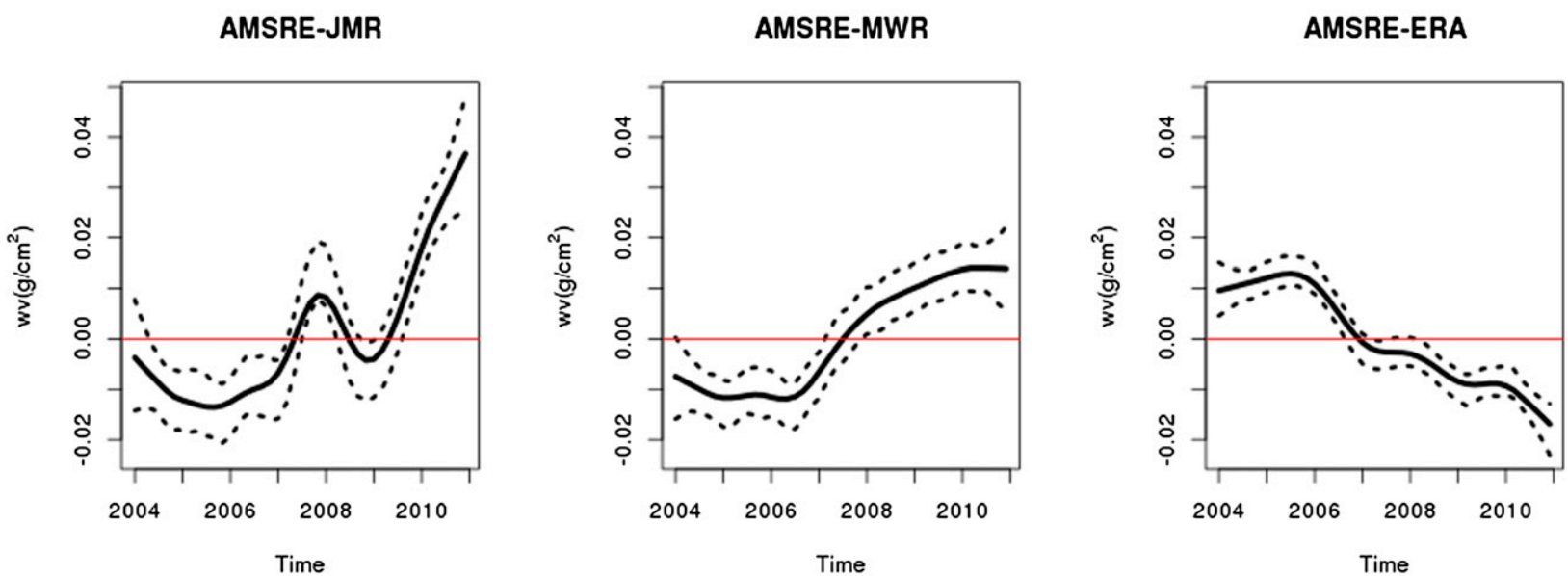

FIG. 7. Nonlinear trends of the anomalies differences time series $\left(\mathrm{g} \mathrm{cm}^{-2}\right)$. The nonlinear trends have been estimated using a loess filter and the $95 \%$ confidence intervals have been built using a sieve bootstrap scheme, considering first-order autoregressive residuals.

Although the differences between AMSR-E and the radiometers or the model increased significantly from 2004 to 2010, the increase did not occur linearly. The nonlinear trends have been estimated using a loess filter and the confidence intervals have been built using the sieve bootstrap scheme (Buhlmann 1996), considering first-order autoregressive residuals (see Fig. 7). While the discrepancies increase between AMSR-E and the three other products, the nonlinear trend analysis shows distinct behaviors in the interannual evolution of the discrepancies. In particular, even though MWR and JMR show a similar linear trend of discrepancies with AMSR-E, the nonlinear trends, which account more for the interannual variations, are different after 2007: with MWR, the differences grow in a logarithmical fashion whereas with JMR, phases where the discrepancies increase and decrease are seen.

\section{c. Space-time dynamics of water vapor}

Although no radiometer leads to the conclusion of an increase of water vapor between 2004 and 2010, quantitative agreement on the trend could not be achieved as the discrepancies between radiometers have increased, though not linearly. Moreover, studies of the average maps of water vapor show that the strongest discrepancies appear in specific regions. The aim of this section is to combine the spatial and the temporal approaches to study dynamical discrepancies. Indeed, the temporal evolution of water vapor is not uniform over the globe. The space-time dynamics of water vapor and the discrepancies between radiometers or the reanalysis are first analyzed through the latitude time series of zonal means.
The time series are presented as Hovmöller diagrams to make the visualization easier. Local trends of water vapor are then compared.

The Hovmöller diagrams of water vapor exhibit a strong annual cycle (Fig. 8). In the same way, differences with AMSR-E also show strong annual variations.

- For JMR, the differences with AMSR-E follow the same pattern as water vapor: the strongest differences appear in areas of important water vapor content. The Hovmöller diagram shows an atypical behavior in November 2006 where the differences are negative. It corresponds to the time when Jason-1 was in safe hold mode from 30 October 2006 to 16 November 2006 (cycles 177 to 179 ).

- For MWR, the strongest differences with AMSR-E appear in high latitudes of both hemispheres alternatively: discrepancy structures appear in each hemisphere in summer. The strong discrepancy structures (in Fig. 3) are therefore not present at the same time in the Northern and Southern Hemispheres. However, the signal is stronger in the Northern Hemisphere.

- For ERA-Interim, the annual variation explains most of the space and time dynamic of the discrepancies. The positive discrepancies in the Southern Hemisphere are stronger in the third trimester of the year. The signal of differences grows stronger in the tropics.

An EOF analysis (not shown) shows that the annual cycle is indeed the main source of variation in the discrepancies. However, it only explains, respectively, $8.0 \%, 5.8 \%$, and $9.9 \%$ of the discrepancy variances for 


\section{Hovmoller diagram of water vapor $\left(\mathrm{g} \mathrm{cm}^{-2}\right)$}

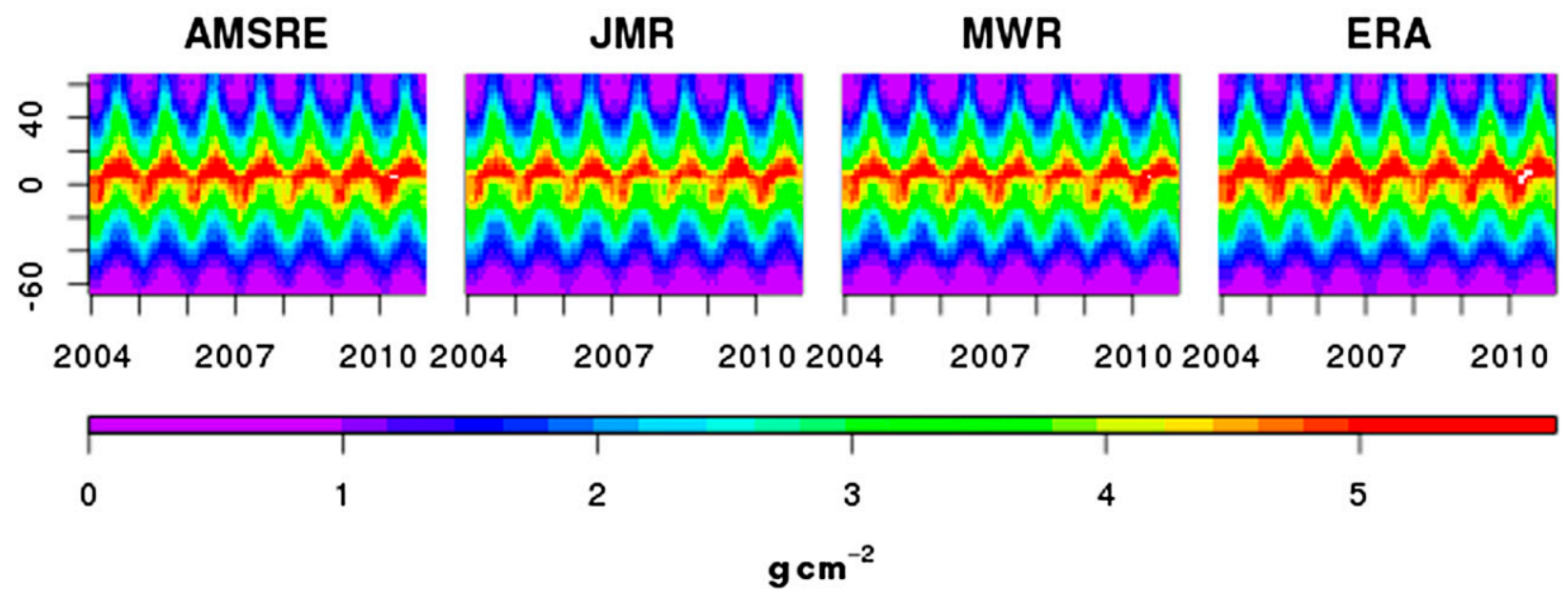

Hovmoller diagram of water vapor differences $\left(\mathrm{g} \mathrm{cm}^{-2}\right)$

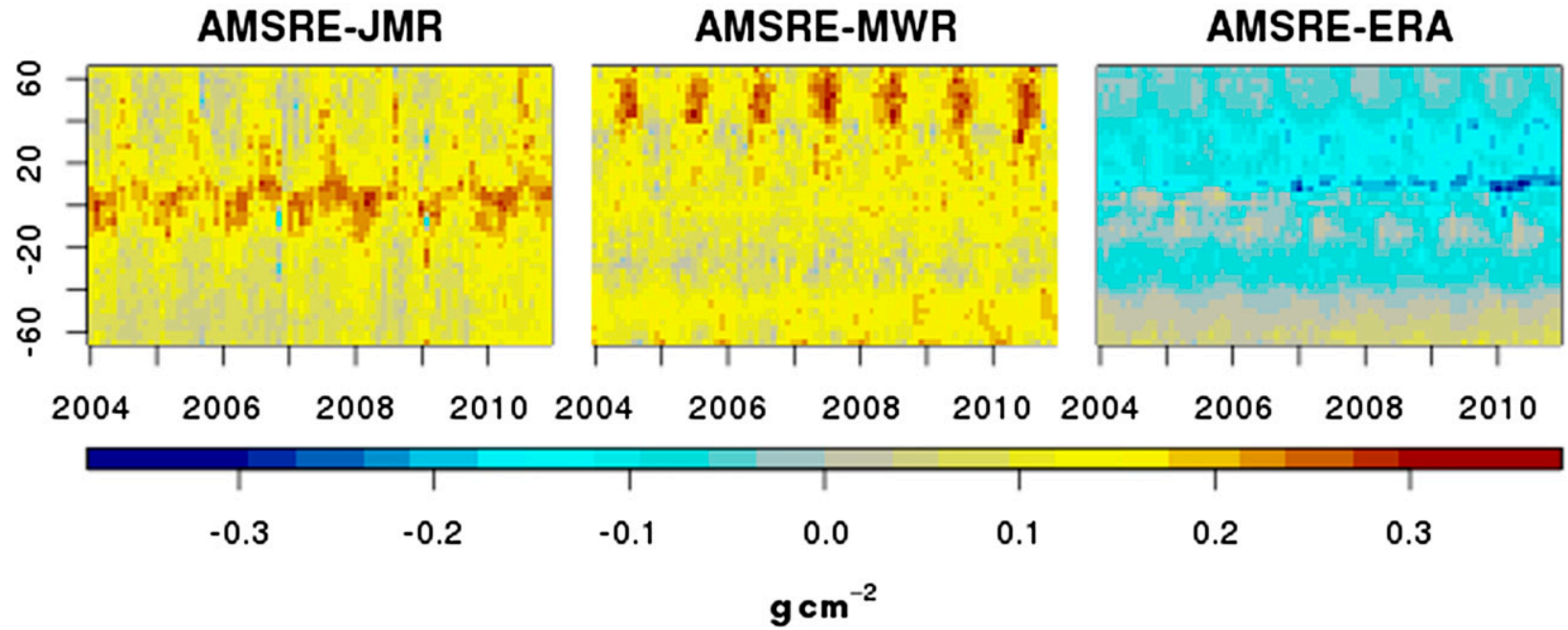

FIG. 8. Hovmöller diagrams of atmospheric water vapor content over oceans $\left(\mathrm{g} \mathrm{cm}^{-2}\right)$ : (top) AMSR-E, JMR, MWR, and ERA-Interim, and (bottom) differences of water vapor between AMSR-E and the other products $\left(\mathrm{g} \mathrm{cm}^{-2}\right)$.

JMR, MWR, and ERA-Interim. It implicates that the differences are composed of small signals or of noise.

Let us consider that differences in the regional annual cycle are systematic errors. Thus, we removed the annual cycle from the maps of anomalies and focus on the monthly anomalies. The monthly anomalies correspond to deviation from the usual annual cycle of water vapor. Therefore, the monthly anomalies reflect changes in the dynamic of water vapor.

The Hovmöller diagrams of monthly anomalies of water vapor exhibit similar patterns for the three radiometers (Fig. 9). The anomalies in the tropics are correlated with ENSO events: anomalies tend to be positive during $\mathrm{El}$
Niño and negative during La Niña. In the three products, the monthly anomalies appear stronger after 2007.

Analyses of the Hovmöller diagrams of monthly anomalies differences show that the discrepancies are not constant through time. Slight changes occur from 2004 to 2010 for each product.

- For MWR, the differences of anomalies with AMSR-E are mostly negative before 2007 and mostly positive after 2007.

- For JMR, four periods can be highlighted: from 2004 to 2007 and from 2008 to 2009, the differences of anomalies with AMSR-E are mainly negative; they are mainly positive otherwise. 


\section{Hovmoller diagram of water vapor anomalies $\left(\mathrm{g} \mathrm{cm}^{-2}\right)$}

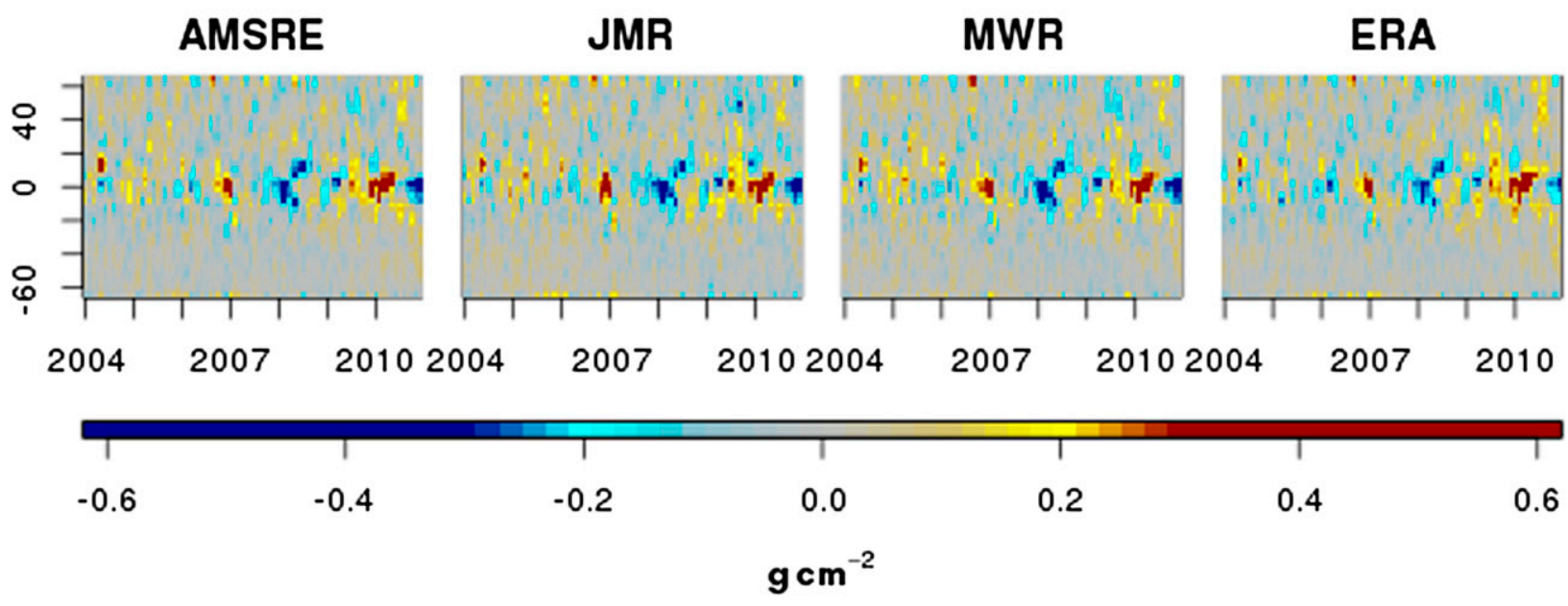

Hovmoller diagram of water vapor anomalie differences $\left(\mathrm{g} \mathrm{cm}^{-2}\right)$

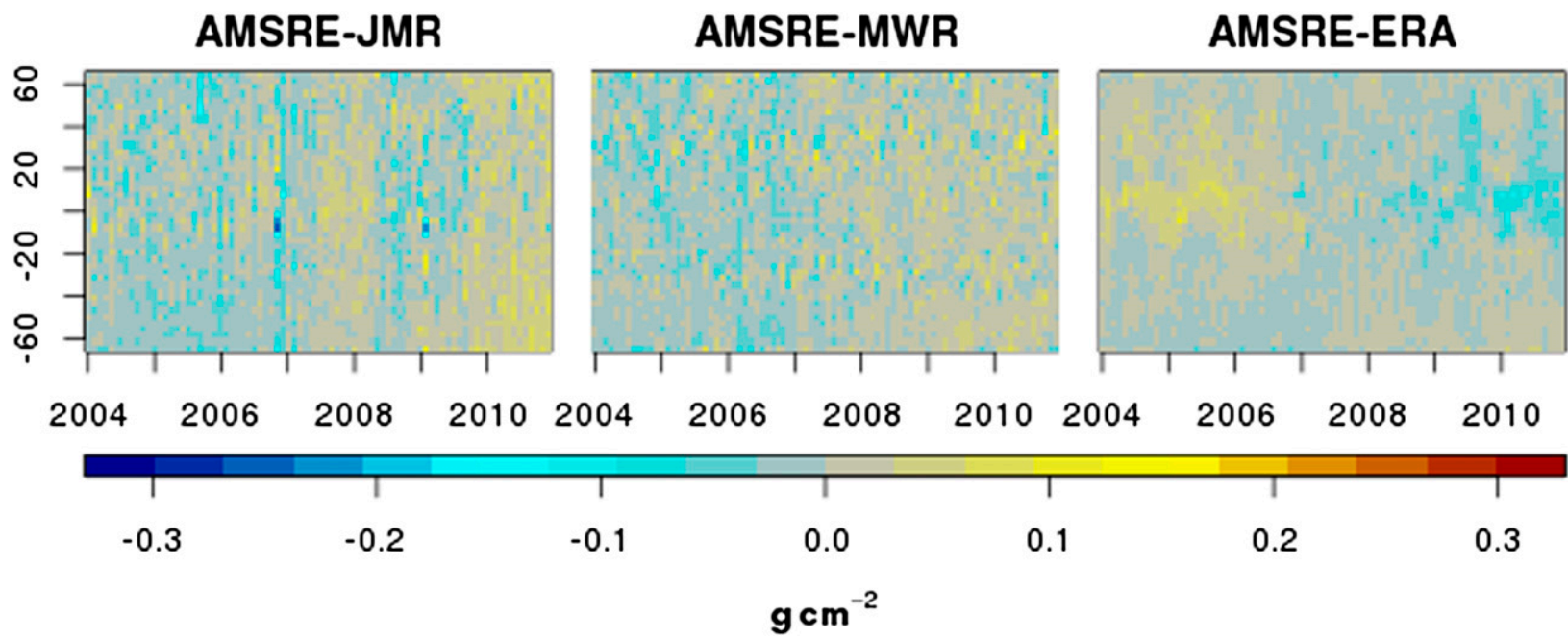

FIG. 9. As in Fig. 8, but for Hovmöller diagrams of atmospheric water vapor content monthly anomalies over oceans $\left(\mathrm{g} \mathrm{cm}^{-2}\right)$.

- For ERA-Interim, the differences are positive in the tropics before 2007 and negative afterward. The differences of anomalies appear stronger in the tropics for the reanalysis.

Those changes were seen in the study of the nonlinear trend of the water vapor anomalies (Fig. 7).

The linear trend of water vapor is computed for each mesh of $3^{\circ}$ (Fig. 10). The four products show good qualitative agreement on the estimation of the regional trends of water vapor. Patterns of trends are influenced by ENSO events in the tropics. The smoothness of the map of trend is the major differences between radiometers for altimetry missions, JMR and MWR, and the large swath radiometer AMSR-E or the ERAInterim reanalysis. Maps from JMR or MWR are less smooth and appear noisier. Areas where trends are significant are similar between the four products. Still, JMR and MWR detect significant trends in high latitudes in the Bering Sea or in the Southern Ocean where AMSRE and ERA-Interim do not.

The trends of differences of water vapor content were also computed for every mesh. For JMR and MWR, the trends are globally underestimated with respect to AMSR-E. For JMR, overestimations of the trend are more located in the tropics, whereas for MWR overestimated 
Regional trends of differences of water vapor $\left(\mathrm{g} \mathrm{cm}^{-2} \mathrm{an}^{-1}\right)$ between 2004 and 2010

(a)

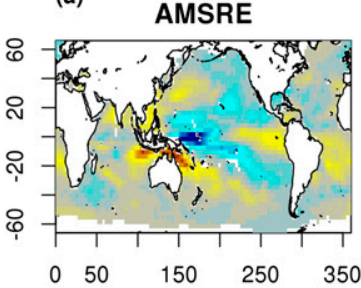

(b)

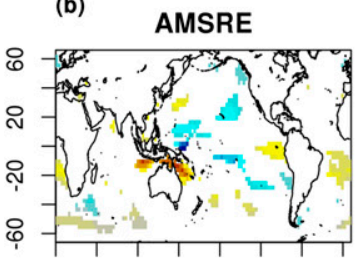

$\begin{array}{llllll}0 & 50 & 150 & 250 & 350 & 0\end{array}$
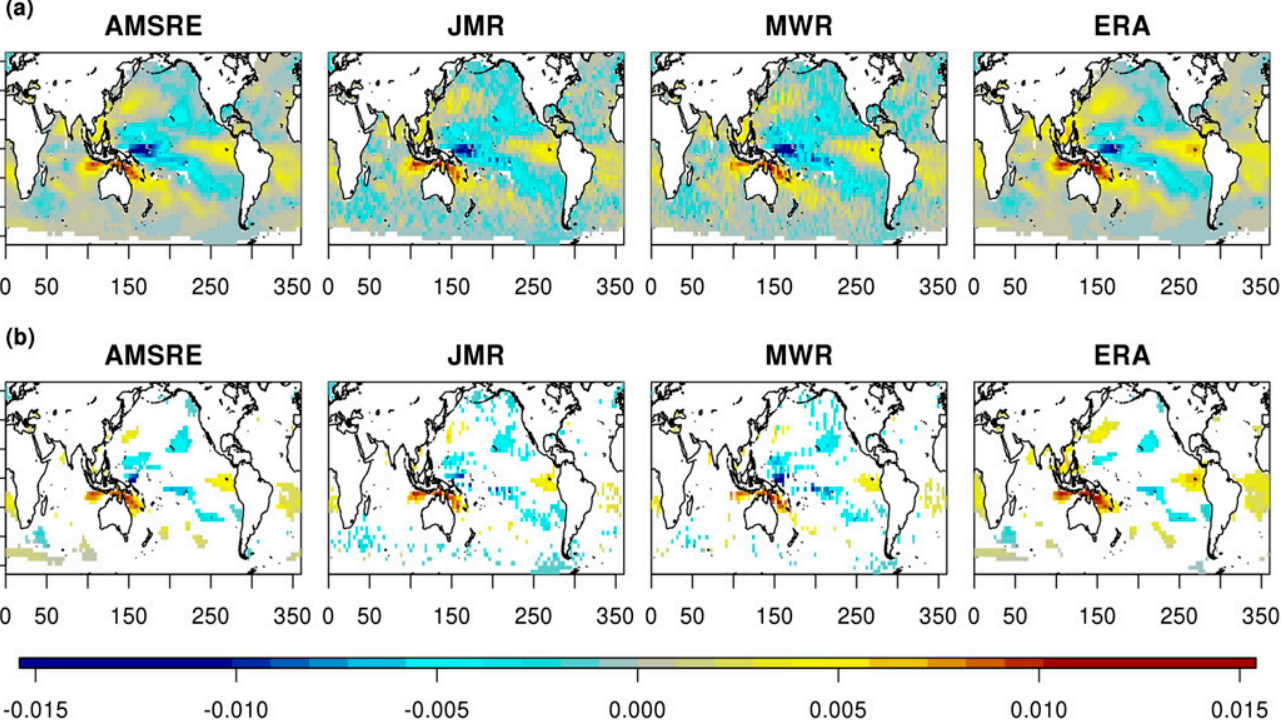

Regional trends of differences of water vapor $\left(\mathrm{g} \mathrm{cm}^{-2} \mathrm{an}^{-1}\right)$ between 2004 and 2010
0.005

0.010

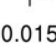

$\mathrm{g} \mathrm{cm}^{-2}$ an $^{-1}$
AMSRE-JMR

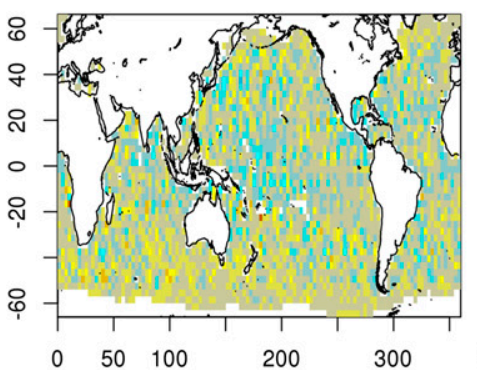

(d)

AMSRE-JMR

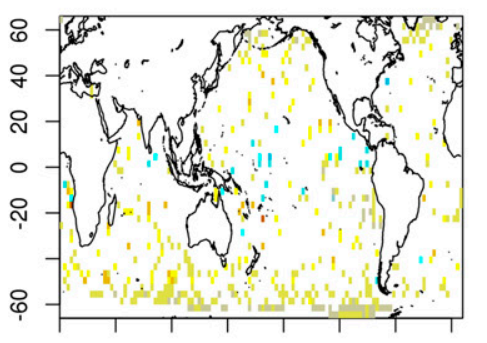

0

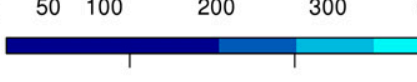

$-0.006$
AMSRE-MWR

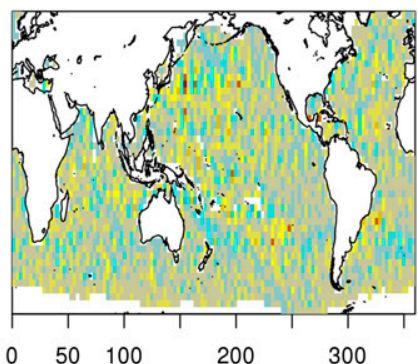

AMSRE-MWR

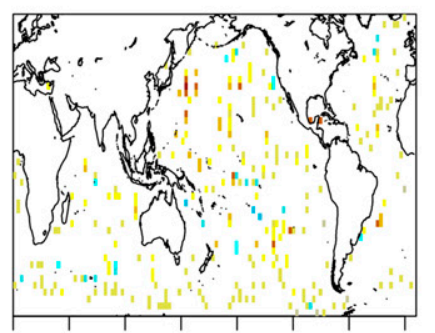

$\begin{array}{llll}0 & 50 & 100 & 200\end{array}$ 
meshes show no particular correlation with latitude. However, very few meshes show significant trend, except in the coasts of Antarctica for JMR. For ERA-Interim, a global overestimation of the trend is seen, especially in the tropics where the differences are significant. Other significant trends are found in the Southern Ocean.

\section{Estimation of the absolute error standard deviation: Triple collocation analysis}

Up to now, only comparative studies have been made using as reference the AMSR-E dataset. However, we are not able to determine which water vapor product is closer to the truth. Indeed, the three radiometer products are relatively close from each other but significant discrepancies are present, especially in terms of longterm trend. In this section, we will not be able to determine which product is of highest quality but we will estimate how large the uncertainty is. Only the random part of the absolute error can be characterized with the triple collocation analysis: absolute systematic errors (absolute biases) are not considered.

The triple collocation analysis was used by Janssen et al. (2007) to estimate the noise (or rather its standard deviation) of three independent sets of measurements made ideally at the same time and place. The principle of triple collocation is hereafter explained. Suppose that the three datasets of measurements $X, Y, Z$ are unbiased and with uncorrelated errors:

$$
\begin{aligned}
& X=T+\varepsilon_{x}, \\
& Y=T+\varepsilon_{y}, \\
& Z=T+\varepsilon_{z},
\end{aligned}
$$

where $T$ is the dataset of the true values of the variable of interest; $\varepsilon_{x}$ (similarly for $\varepsilon_{y}$ and $\varepsilon_{z}$ ) is the measurement error and is represented by a random variable of null mean and variance $\sigma_{x}^{2}\left(\right.$ or $\sigma_{y}^{2}$ or $\left.\sigma_{z}^{2}\right)$ and $\operatorname{cov}\left(\varepsilon_{i}, \varepsilon_{i^{\prime}}\right)=$ 0 , for $i \neq i^{\prime}$ and $\left(i, i^{\prime}\right) \in\{x, y, z\}^{2}$. Here cov and var, respectively, denote the empirical covariance and variance operator. It assumes that, for one radiometer, the noise is spatially homogeneous (which is probably not the case in reality).

Then $\sigma_{x}^{2}, \sigma_{y}^{2}$, and $\sigma_{z}^{2}$ can be estimated by

$$
\begin{aligned}
\sigma_{x}^{2} & =1 / 2[\operatorname{var}(X-Y)+\operatorname{var}(X-Z)-\operatorname{var}(Y-Z)], \\
\sigma_{y}^{2} & =1 / 2[\operatorname{var}(Y-X)+\operatorname{var}(Y-Z)-\operatorname{var}(X-Z)], \\
\sigma_{z}^{2} & =1 / 2[\operatorname{var}(Z-X)+\operatorname{var}(Z-Y)-\operatorname{var}(X-Y)] .
\end{aligned}
$$

Janssen et al. (2007) used the method with match-ups and it gave the radiometer noise for one measurement. Here, the method could not exactly be used as Janssen et al. (2007) did, since the number of crossovers with the chosen missions is scarce. Thus, it was decided to decrease the spatial and time resolution of our data. Every measurement made within the same bin and within the same month is considered to be taken at same time and place. The measurements are averaged to provide the state of water vapor at a given month and at a given bin. With this transformation, the method could be applied to monthly binned maps. However, the method no longer evaluates the radiometer noise for one given measurement but the average noise of one bin at a given month. That includes both the incertitude due the radiometer noise and the spatial and temporal sampling of the measurements.

Even if the analysis does not provide a direct estimation of the radiometer measurement noise for each corresponding altimeter sea level height measurement, it is possible to check that the sum of the radiometer noise and the sampling noise remains stable over time. Let us note that, in normal conditions, the sampling noise for one mission should remain stable or should at least vary deterministically since the mission orbits are repetitive. Uncertainties as to the estimated state of water vapor for a given month, due to missing data or changes of orbit, can be evaluated using this method. Such uncertainties can be taken into account when trends are computed, for instance. Noise variations unrelated to the sampling scheme of the mission can be attributed to changes in the measurement noise. Assessing the product uncertainties regarding sampling or instrumental noises is especially important when several products are merged to construct a common reference dataset.

The triple collocation is first applied to AMSR-E, MWR, and JMR. However, we can assume, looking at the scatterplots in Fig. 4, that at least one water vapor product is biased. Thus, (7) cannot be used directly. We assume (even if it is obviously not true) that for each product the relative bias between instruments is linear in function of the water vapor content. Here, the analysis is made with the three radiometer datasets and following the former assumption we have

$$
\begin{aligned}
\mathrm{wv}_{\mathrm{AMSRE}} & =b_{\mathrm{AMSRE}} \times T+a_{\mathrm{AMSRE}}+\varepsilon_{\mathrm{AMSRE}}, \\
\mathrm{wv}_{\mathrm{MWR}} & =b_{\mathrm{MWR}} \times T+a_{\mathrm{MWR}}+\varepsilon_{\mathrm{MWR}}, \\
\mathrm{wv}_{\mathrm{JMR}} & =b_{\mathrm{JMR}} \times T+a_{\mathrm{JMR}}+\varepsilon_{\mathrm{JMR}} .
\end{aligned}
$$

where $T$ is the true value of the water vapor to be measured; $a_{i}$ and $b_{i}$, with $i \in\{$ AMSRE, MWR, JMR $\}$, are called adjustment coefficients.

By subtracting $a_{i}$ from $\mathrm{wv}_{i}$ and then dividing by $b_{i}$ for all $i \in\{$ AMSRE, MWR, JMR $\}$, an equation with a form similar to (6) is obtained: 


\section{Triple Collocation Analysis}

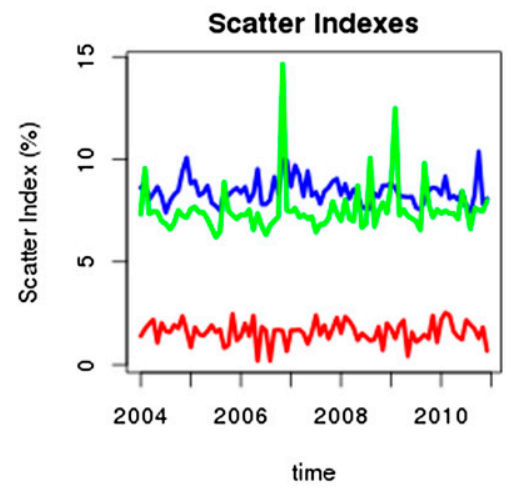

AMSRE

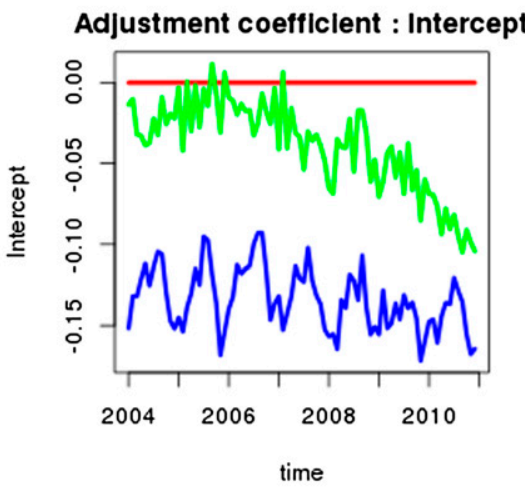

MWR

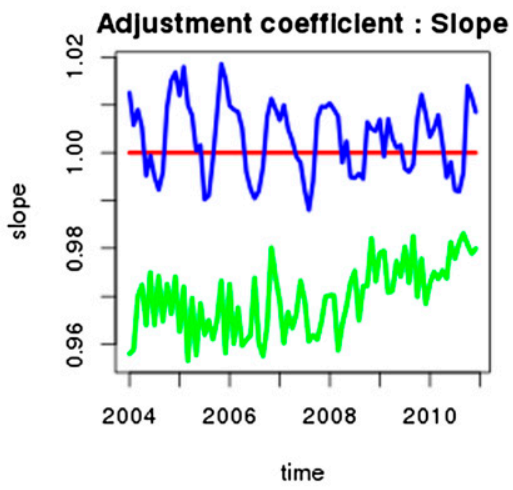

JMR

FIG. 11. Results of the triple collocation between AMSR-E, MWR, and JMR: (left) monthly scatter index (i.e., the ratio between the standard deviation of the errors and the average water vapor signal); (\%), (middle) evolution of the adjustment coefficient $b$ (without unit), and (right) the evolution of the adjustment coefficient $a\left(\mathrm{~g} \mathrm{~cm}^{-2}\right)$.

$$
\begin{aligned}
\mathrm{wv}_{\mathrm{AMSRE}}^{\prime} & =T+\frac{\varepsilon_{\mathrm{AMSRE}}}{b_{\mathrm{AMSRE}}}=T+\varepsilon_{\mathrm{AMSRE}}^{\prime}, \\
\mathrm{wv}_{\mathrm{MWR}}^{\prime} & =T+\frac{\varepsilon_{\mathrm{MWR}}}{b_{\mathrm{MWR}}}=T+\varepsilon_{\mathrm{MWR}}^{\prime}, \\
\mathrm{wv}_{\mathrm{JMR}}^{\prime} & =T+\frac{\varepsilon_{\mathrm{JMR}}}{b_{\mathrm{JMR}}}=T+\varepsilon_{\mathrm{JMR}}^{\prime} .
\end{aligned}
$$

Then, (7) can be used to estimate $\sigma_{\mathrm{AMSRE}}^{2}, \sigma_{\mathrm{MWR}}^{2}$, and $\sigma_{\mathrm{JMR}}^{2}$, the variance of $\varepsilon_{\mathrm{AMSRE}}^{\prime}, \varepsilon_{\mathrm{MWR}}^{\prime}$, and $\varepsilon_{\mathrm{JMR}}^{\prime}$.

However, the adjustment coefficients are unknown since the truth is unknown. Hence, we choose one of the products as reference: in this case, AMSR-E. Then, MWR and JMR products are calibrated with respect to AMSR-E. This means that MWR and JMR data are linearly adjusted so as to be the closest to AMSR-E data. The adjustment coefficients are computed by regressing MWR (or JMR) with respect to AMSR-E. Since both MWR (or JMR) and AMSR-E products contain an error, total least squares regression is used.

The total least squares regression solutions depend on $\sigma_{\mathrm{AMSRE}}^{2}, \sigma_{\mathrm{MWR}^{\prime}}^{2}$, and $\sigma_{\mathrm{JMR}}^{2}$. Thus, an iterative scheme is used. First, we assume that all products are wellcalibrated ( $\forall i \in\{$ AMSRE, EN, J1 $\left.\}, a_{i}=0, b_{\mathrm{i}}=1\right)$ and a first estimation of $\sigma_{\mathrm{AMSRE}}^{2}, \sigma_{\mathrm{MWR}^{\prime}}^{2}$, and $\sigma_{\mathrm{JMR}}^{2}$ is computed. The estimations of $\sigma_{\mathrm{AMSRE}}^{2}, \sigma_{\mathrm{MWR}}^{2}$, and $\sigma_{\mathrm{JMR}^{\prime}}^{2}$ are then used to deduce the adjustment coefficients $b_{\mathrm{MWR}}, a_{\mathrm{MWR}}, b_{\mathrm{JMR}}$, and $a_{\mathrm{JMR}}$. As the reference, the adjustment coefficients of AMSR-E are unchanged. The scheme is iterated until convergence of the parameters is reached. One can show that the final estimations of $\sigma_{\text {AMSRE }}^{2}, \sigma_{\text {MWR }}^{2}$, and $\sigma_{\text {JMR }}^{2}$ do not depend on the reference used.
An estimation of $\sigma_{\text {AMSRE, }}^{2} \sigma_{\text {MWR }}^{2}$, and $\sigma_{\text {JMR }}^{2}$ is made for each month using the triple collocation technique and is presented as scatter indexes (Fig. 11, left panel). The scatter index is computed as the ratio between the standard deviation of the error and the mean of the signal value. It is a proxy of how much the signal is affected by noise. AMSR-E has the lowest scatter index, indicating lower errors than the two other missions. The noise is smaller than $3 \%$ of the signal received by AMSR-E whereas for MWR and JMR, the error represents around $10 \%$. JMR has globally a slightly lower scatter index than MWR but suffers from unusually high peaks in November 2006, August 2008, and February 2009 where a high number of missing data is present. Jason-1 was in safe hold mode for half of November 2006 (cycles 177 to 179). Nearly 85 out of 254 passes were missing for cycle 242 in August 2008. Jason-1 was put on a new interleaved orbit at the end of January 2009 and no data were provided from 26 January 2009 to 10 February 2009 (cycles 260 and 261).

Middle and right panels show the adjustment coefficients for each month. Since AMSR-E is the reference, its coefficients remain constant. MWR coefficients follow an annual cycle but no strong trend is observed. The annual cycle in the calibration coefficient is consistent with the annual cycle of the discrepancies between AMSR-E and MWR. The slope coefficient and the intercept coefficient for the calibration of JMR respectively follow an increasing and decreasing trend after 2008. Thus, differences of strong water vapor content are increasing, as it is visible on a map of local trend differences.

The analysis is reiterated with the ERA-Interim as reference and the comparison is made with AMSR-E 


\section{Triple Collocation Analysis}
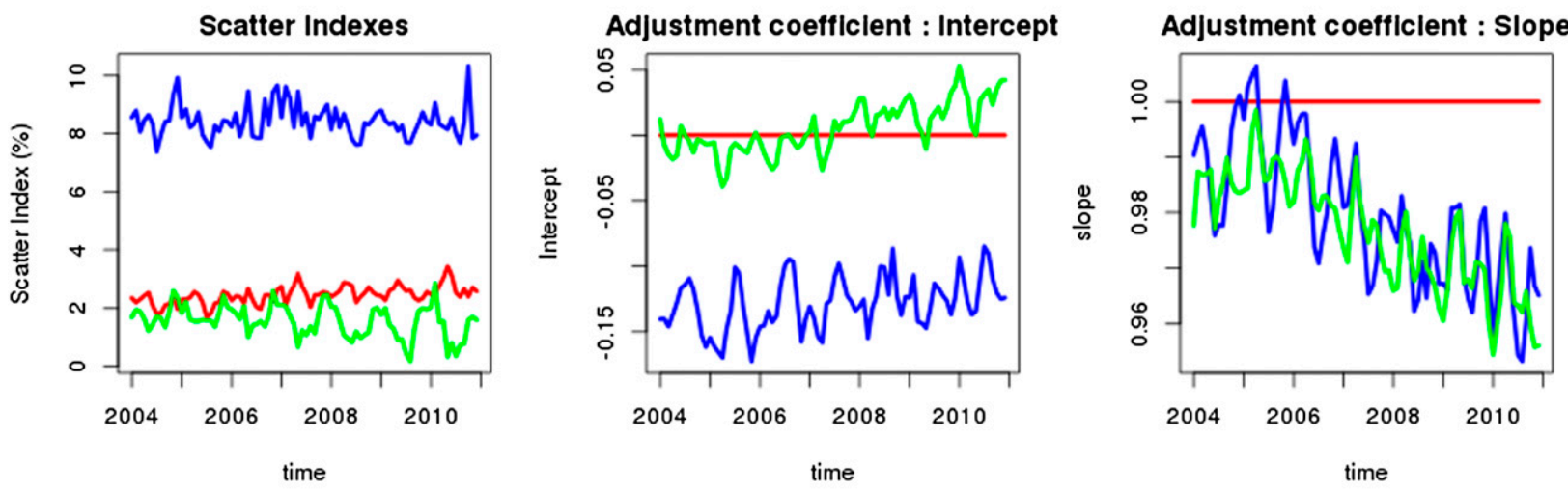

ERA

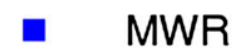

AMSRE

FIG. 12. Results of the triple collocation of ERA-Interim, MWR, and AMSR-E. (left) The monthly scatter index (i.e., the ratio between the standard deviation of the errors and the average water vapor signal); (\%). (middle) The evolution of the adjustment coefficient $b$ (without unit). (right) The evolution of the adjustment coefficient $a\left(\mathrm{~g} \mathrm{~cm}^{-2}\right)$.

and MWR. The choice of ERA-Interim as reference instead of AMSR-E is only made for visualization purposes and has no impact on the scatter index estimations. Indeed, keeping AMSR-E as a reference would lead to the same scatter index estimations, although the calibration coefficients would change. However, introducing ERA-Interim in the triple collocation instead of JMR impacts the scatter index estimations since ERA-Interim and JMR exhibit different levels of noise. Indeed, the scatter indexes estimated for AMSR-E have changed: an annual cycle is now visible but the average scatter index for AMSR-E remains around 2\% (Fig. 12, left panel). The estimation of the MWR scatter index is however not affected by the substitution of JMR by ERA-Interim.

For ERA-Interim, the scatter index estimation is slightly higher than for AMSR-E, but is more stable through time. As for the adjustment coefficient, the AMSR-E and MWR datasets need similar adjustments to fit the ERA-Interim dataset (Fig. 12, middle and right panels). Their slope coefficients are decreasing in a similar way and the intercept coefficients are slightly increasing. Thus, there is a gradual change in the statistical distribution of water vapor provided by the reanalysis which is not observed by the radiometers. For both radiometers, an annual cycle is visible for the adjustment coefficients although the ones from MWR show higher variations. The triple collocation has also been used with other combinations of radiometers and ERA-Interim and similar results were obtained.

Overall, this analysis shows that AMSR-E and ERAInterim estimations of monthly water vapor are less affected by noise that JMR or MWR and that the statistical distribution of water vapor evolves differently for each product. However, those conclusions have to be taken with care as not all assumptions are verified, especially the linear relationship between the truth and the different measurements. The parameterization of the intercalibration has to take into account the nonlinear relationships between the measurements.

\section{Interpretation and discussion}

\section{a. Interpretation of the results}

In terms of long-term trend, neither the radiometers nor ERA-Interim could show a significant change in water vapor. The detection of a long-term trend of this amplitude is difficult because, during this period, the variance of the residuals outweighs the variations explained by the long-term trend. Mieruch et al. (2008) explains that high variability of the residuals and their strong autocorrelation is likely due to ENSO events. In this analysis of the water vapor trend between 1995 and 2008, the trend was shown insignificant when strong ENSO events were kept but significant when removed. As a matter of fact, a strong El Niño event occurs at the beginning of 2010 according to the multivariate ENSO index, and the amplitude of the water vapor anomalies differs between the radiometers during this period. However, it is unclear whether strong ENSO events should be removed as ENSO events may reflect changes in the water vapor distribution.

However, the trend differences between the radiometers or the model are significant, meaning that the 
differences between AMSRE and JMR or MWR or ERA-Interim have increased during this period. For instance, the discrepancies of trends between AMSR-E and MWR or JMR are about as high as $0.005 \mathrm{~g} \mathrm{~cm}^{-2} \mathrm{yr}^{-1}$. Using the empirical relationship (2), it represents approximately an equivalent trend in wet tropospheric path delay of $0.3 \mathrm{~mm} \mathrm{yr}^{-1}$, which corresponds to onetenth of the MSL trend between 1992 and 2011 estimated by Ablain et al. (2009). It also corresponds to the uncertainty on the wet tropospheric path delay estimated in the same study.

It is important to note that, due to the short period covered in this study, the estimation of the linear trend is highly influenced by interannual dynamics. Moreover, a good agreement on the linear trend of water vapor does not necessarily denote a good consistency between the products. For instance, JMR and MWR products exhibit really similar linear trends but the analysis of the nonlinear trend shows small but significant differences in behavior on the interannual scale.

With the exception of the estimation of product intrinsic noise via the triple collocation method, only relative errors were obtained since only comparison study were made. Thus, the characterization of absolute errors remains difficult. However, those comparisons help to form hypotheses to explain the origins of the observed discrepancies. For instance, in terms of geographical errors, the observed patterns of differences between AMSR-E and one of the water vapor products do not appear in the other comparisons. Thus, compared to the other products, AMSR-E did not exhibit abnormal behavior. We can assume that the observed discrepancies are likely due to the other products. On the contrary, the strong pattern of discrepancies in high latitudes between AMSR-E and MWR also appears in the differences between MWR and JMR, and between MWR and ERA-Interim (not shown). In this case, the origin of those differences can be attributed to MWR.

For JMR, the differences with AMSR-E increase with the water vapor content. Thus, the largest differences are found in the tropics. The space-time dynamics of the difference follows the annual cycle of water vapor. The strong relationship between the discrepancies and the water vapor may indicate a retrieval algorithm deficiency for the high contents of water vapor. The algorithm used in JMR to retrieve the water vapor content from the measured wet tropospheric path delay probably introduce geographically correlated biases as the two quantities are not totally equivalent. For instance, Zlotnicki and Desai (2004) empirically deduced the wet tropospheric correction from water vapor products of TMI and SSM/I radiometers to assess JMR wet path delay accuracy. The authors reported that such transformation introduces geographical biases but those should not affect the observed time variability of water vapor. Finally, the unstable adjustment coefficients found in the triple collocation analysis suggest a possible drift of the JMR radiometer.

For MWR, the largest differences concern coastal regions of the Northern Hemisphere and upwelling areas. They follow an annual cycle with a peak in summer. Upwelling areas are problematic for statistical retrieval algorithm as they show very specific temperature and humidity profiles. Obligis et al. (2009) showed that MWR retrieval of water vapor could be improved in those areas by taking into account additional information on the atmospheric stratification. However, the regional patterns of discrepancies followed an annual cycle: the discrepancies only appear in summer in each hemisphere. Moreover, the triple collocation analysis confirm the change in the relative distribution of discrepancies between AMSR-E and MWR with respect to water vapor from AMSR-E, as the adjustment coefficients show a strong annual cycle. An empirical correction has been used for MWR to take into account the contribution of land in the measured brightness temperatures. The contributions have been calculated using estimated reflection coefficients of the platform (Obligis et al. 2007). Correction tables are available for each frequency and for each season to account for the annual variations in land emissivity. An overcorrection of the sidelobe contamination by land could explain the presence of discrepancies in coastal areas at high latitudes and their annual dynamics. The hypothesis is also consistent with the fact that the discrepancies are strong in the Northern Hemisphere since the proportion of land is higher.

For ERA-Interim, the water vapor content and the trend are globally overestimated with respect to AMSRE. The differences are especially strong in the tropics, especially in the intertropical convergence zone. This region is characterized by the presence of convective clouds and heavy rainfalls. These conditions make the estimation of water vapor more difficult for radiometers and models. On the one hand, simulation of clouds and precipitation (and notably tropical convection) is still among the major problems that face numerical weather prediction models. On the other hand, the water vapor estimations from radiometers can be biased in this area as radiometer measurements of water vapor are edited as nonvalid in heavy rain conditions. The uncertainties are thus larger in such areas. Only the water vapor content in the Southern Ocean is underestimated. In this region, the differences are stronger in the third trimester of the year where the sea ice extent is the largest (Parkinson and Cavalieri 2012). Therefore, those discrepancies may 
be related to sea ice. Dee et al. (2011) explain the difficulty to assess the quality of trend derived from ERAInterim in polar and tropical regions due to the lack of high-quality observations in these areas. The triple collocation analysis shows that MWR and AMSR-E need similar adjustment through time to fit the statistical distribution of water vapor from ERA-Interim, suggesting that the estimation of water vapor from ERAInterim is not stable.

Space and time sampling play an important role in the estimation of the monthly state of water vapor as well as for the estimation of local trends. The triple collocation showed that the accuracy was better for AMSR-E and ERA-Interim than for JMR or MWR to estimate monthly maps of water vapor at resolution of $3^{\circ}$. Noise is probably lower in AMSR-E since the number of measurements per bin for AMSR-E is much more important than for the two other radiometers. Indeed, AMSR-E has a better coverage of Earth surface thanks to its large swath. The difference of time and space sampling is also seen on the local trends of water vapor where the estimated maps show less noise and better consistency between close meshes. The ERA-Interim reanalysis also show good geographical consistency between the local trends estimated thanks to high spatial and time resolution. The number of available measurements per month also impacts the confidence in the estimation of the integrated water vapor. For instance, the triple collocation showed that for JMR the noise increases by 2 times when half of the data were missing in November 2006. Thus, less confidence should be granted to JMR in November 2006 when computing, for example, the long-term trend.

Finally, only aggregate data were used in the comparison: the measurements were averaged by months in meshes of $3^{\circ}$ and none of the measurements was directly compared without transformation. Thus, by averaging measurements by month, we lost the ability to study variations of water vapor with a temporal scale lower than a month and especially the diurnal cycle of water vapor. Furthermore, we expect that the averaged measurements are representative of the water vapor state within a month. However, such an assumption may be wrong as the full diurnal cycle of water is not considered. Aqua and Envisat are satellites with sun-synchronous orbits. Such satellites ascend or descend over any given Earth latitude at the same local mean solar time. On the contrary, for Jason-1, which is not sun-synchronous, the local successive pass time is shifted $2 \mathrm{~h}$ about every 10 days. Dai et al. (2002) show that the nonrepresentativeness of the diurnal sampling of water vapor leads to additional errors in the monthly mean of water vapor: twice-daily sampling (at 0000 and 1200 UTC) by soundings adds an error of about $3 \%$ of the signal while one random sounding per day raises the error up to $10 \%$ of the signal.

\section{b. Expected impacts on the wet tropospheric path delay}

The remaining question is whether the discrepancies seen in the water vapor products can be related to wet tropospheric path delay errors or uncertainties. It was explained that the integrated water vapor content and the wet tropospheric path delay are not equivalent quantities as the wet tropospheric path delay is also influenced by the atmospheric profile of water vapor. However, the two physical quantities are strongly correlated. Following Eq. (1) and Fig. 1, the wet tropospheric path delay can statistically be seen as a water vapor signal disturbed by a signal of smaller amplitude: the atmospheric profiles of pressure and temperature. Thus, it is possible to statistically model the wet tropospheric path delay as

$$
d h=k \times \mathrm{wv}+\varepsilon,
$$

where $d h$ is in centimeters and wv is in grams per centimeter squared, $k$ is a real number in cubed centimeters per gram, and $\varepsilon$ is in centimeters, with the disturbance due to the atmospheric profile. The variance of $\varepsilon$ depends on wv and its mean is considered null.

Thus, by averaging a large number of measurements over the whole globe, the noise factor can be neglected and the path delay and the water vapor considered as equivalent. That explains why the times series of water vapor and the wet tropospheric path delay are strongly correlated. Hence, the discrepancies in the global times series of water vapor are expected to impact accordingly the global time series of the wet tropospheric path delay.

In terms of geographical distribution, water vapor and the wet tropospheric path delay exhibit a strong similarity. However, discrepancies at the regional scales are present when unusual profiles of temperature and humidity are met (e.g., upwelling areas). If the formalism describe in (10) is kept, the differences of water vapor between two radiometers at the same grid point should be observable in the path delay products as long as the differences in the atmospheric profiles seen by the radiometers are small.

In addition, let us note that the water vapor or the path delay are mainly derived from the brightness temperatures around $23.8 \mathrm{GHz}$. The brightness temperature at $23.8 \mathrm{GHz}$ is almost linear with the integrated water vapor and the wet path delay. The other inputs are used from additional adjustments of smaller amplitude. Therefore, if discrepancies between two water vapor products are observed and are assumed to come from calibration issues or drifts in the brightness temperatures at $23.8 \mathrm{GHz}$, 
the wet path delay is also expected to be impacted in a similar way.

However, if the strong and almost linear relationship between water vapor and the wet path delay is not taken into account the same way in the different retrieval processes, it may not be possible to infer discrepancies in the wet path delay products from discrepancies in the water vapor products. Significant discrepancies, which are intrinsic to the retrieval algorithms used, could increase, reduce, or even hide the impact of water vapor differences on the differences of the wet tropospheric path delay.

In consequence, it is likely that the discrepancies observed in the global time series of water vapor are also present in the global time series of the wet path delay. Trend differences should also be observable in the wet tropospheric path delay products.

For MWR, we have suggested that the differences in high latitudes and coastal areas are likely due to an overcorrection of the sidelobe land contribution. In this case, those differences should also appear in the analysis of brightness temperatures but also in the wet path delay products.

For JMR, the bias between AMSR-E and JMR scales with water vapor. If the bias is related to calibration issues (e.g., brightness temperatures of JMR are higher than brightness temperatures of AMSR-E for high values), a similar bias should also be observed in the path delay products. If the bias comes from the retrieval procedure, the bias might not sign on the wet tropospheric path delay. In the case of JMR, the water vapor is directly deduced from the wet tropospheric path delay. Thus, if the transfer function, to pass from path delay to water vapor, is close to linear, then the bias should be seen both on the path delay and the water vapor products. A calibration drift of the brightness temperatures was also suspected in JMR. In this case, the discrepancies should also impact the wet path delay products.

\section{Conclusions and perspectives}

This paper presents the comparison of independent water vapor products from three radiometers: AMSR-E on Aqua, JMR on Jason-1, and RA2-MWR on Envisat, for the period 2004-10. Complementary statistical analyses have been used to qualify and quantify the relative and absolute errors of the products and to assess the precision of the wet tropospheric path delay.

The results have shown good qualitative agreement between the three radiometers and ERA-Interim: they show that water vapor is spatially organized mainly with respect to latitude, that the main variation of water vapor is due to the annual signal, and that the interannual variation in the tropics is mainly related to ENSO events. However, quantitative discrepancies remain as the strength and amplitude of each signal differ from one product to another.

Those differences significantly impact the estimation of MSL trend. For instance, the difference of trend between AMSR-E and MWR is around $0.005 \mathrm{~g} \mathrm{~cm}^{-2} \mathrm{yr}^{-1}$, which is significant with respect to the accuracy required for the MSL issue. Indeed, it represents a difference in the wet tropospheric path delay trend of about $0.32 \mathrm{~mm} \mathrm{yr}^{-1}$, about one-tenth of the MSL trend between 1992 and 2011. It is within the incertitude range on the wet tropospheric trend evaluated and estimated at $0.3 \mathrm{~mm} \mathrm{yr}^{-1}$ by Ablain et al. (2009). However, despite the three products having different trends, none of the time series analyses of the water vapor products led to the conclusion that the water vapor content has significantly increased or decreased between 2004 and 2010.

Part of the behavior of the discrepancies with respect to AMSR-E has been characterized temporally and spatially. In this respect, the choice of AMSR-E as reference is, a posteriori, reasonable as it did not show any abnormal behavior with respect to the other products.

- For JMR, the discrepancies increase with the water vapor content. Thus, the largest differences concern the tropical regions and fluctuate according to an annual cycle. The discrepancies, which highly depend on the values of the water content, may be related to algorithm or calibration issues. Moreover, those discrepancies seem to grow over time, which would indicate a drift in JMR radiometer.

- For MWR, the discrepancies are stronger in coastal regions of the Northern Hemisphere. The discrepancies also follow an annual cycle with a peak in summer. These observations are consistent with a possible overestimation of the sidelobe land contamination for the MWR radiometer, especially during summer.

- For ERA-Interim, the water vapor content is globally overestimated. The differences are especially strong in the tropics. Only the water vapor content in the Southern Ocean is underestimated. Differences of statistical distribution of water vapor increased from 2004 to 2010.

Finally, triple collocation analysis has shown that the AMSR-E system had more potential to produce accurate monthly maps of water vapor since the conicalscanning system improves the coverage of the oceans.

The construction of a better product remains a challenge. Indeed, while this analysis helps to form hypotheses 
to explain the observed discrepancies between products, the exact identification of errors and their causes remains difficult: each product is the result of a complex multistep process and the differences, although significant, are relatively small. Further investigations are required to confirm or refute the hypothetical explanations that were raised in this paper. To do so, it is first necessary to identify the meteorological and oceanographic conditions that induce important discrepancies in the retrieval of water vapor. Those discrepancies may be related to differences in the instruments or mission designs or ground processing (sampling, in-flight calibration, retrieval algorithms, and editing criteria). Comparison of the radiometers' responses to those problematic situations will help us to distinguish instrumental or processing issues from natural variability of water vapor. Knowing more about each radiometer's behavior relative to the measure of water vapor will bring new insights to the issue and may hopefully lead to better diagnostics of the water vapor evolution. Impacts of sea surface temperature, wind speed, cloud water, rain rate, and unusual profiles of pressure and temperature are also to be explored.

For climatic studies, such analyses need to be extended beyond the 2004-10 period. Understanding the advantages and disadvantages of each water vapor product is a necessity when radiometer datasets are to be merged. For now, building a reference dataset of water vapor seems hardly realizable as the uncertainties related to discrepancies in the mission characteristics or in the data processing are not well understood. However, the objective is to at least provide homogeneous and consistent datasets. Data from different radiometers need to be retreated within a common framework, from the calibration of the brightness temperatures to the estimation of water vapor, to minimize the effect of the methodology used. It is important not to produce only one homogenous dataset that will serve as reference, but a multitude of them using different processing methods to assess how much the results depend on the method. Finally, having homogenous datasets of water vapor would also help improve the wet tropospheric path delay. Consistency between the two physical quantities is a first prerequisite to assess the quality of long time series of wet tropospheric path delay.

Acknowledgments. This study has been founded by the CNES. AMSR-E data are produced by Remote Sensing Systems (RSS) and sponsored by the NASA Earth Science Measurements DISCOVER Project and the AMSR-E Science Team. Data are available at www. remss.com. Jason-1 and Envisat data are available at the
AVISO data center (http://www.aviso.oceanobs.com). The ERA-Interim data are provided by ECMWF.

\section{REFERENCES}

Ablain, M., A. Cazenave, G. Valladeau, and S. Guinehut, 2009: A new assessment of the error budget of global mean sea level rate estimated by satellite altimetry over 1993-2008. Ocean Sci., 5, 193-201, doi:10.5194/os-5-193-2009.

Brown, S., S. Desai, S. Keihm, and W. Lu, 2009: Microwave radiometer calibration on decadal time scales using on-Earth brightness temperature references: Application to the TOPEX Microwave Radiometer. J. Atmos. Oceanic Technol., 26, 25792591, doi:10.1175/2009JTECHA1305.1.

Buhlmann, P., 1996: Confidence regions for trends in time series: A simultaneous approach with a sieve bootstrap. University of California, Berkeley, Department of Statistics, Rep. 447, 27 pp. [Available online at http://statistics.berkeley.edu/ tech-reports/447.]

Dai, A., J. Wang, R. H. Ware, and T. V. Hove, 2002: Diurnal variation in water vapor over North America and its implications for sampling errors in radiosonde humidity. J. Geophys. Res., 107 (D10), doi:10.1029/2001JD000642.

Dee, D. P., and Coauthors, 2011: The ERA-Interim reanalysis: Configuration and performance of the data assimilation system. Quart. J. Roy. Meteor. Soc., 137, 553-597, doi:10.1002/qj.828.

Eymard, L., E. Obligis, N. Tran, F. Karbou, and M. Dedieu, 2005: Long-term stability of ERS-2 and TOPEX Microwave Radiometer in-flight calibration. IEEE Trans. Geosci. Remote Sens., 43, 1144-1158, doi:10.1109/TGRS.2005.846129.

Fu, L.-L., and A. Cazenave, 2000: Satellite Altimetry and Earth Sciences: A Handbook of Techniques and Applications. Academic Press, 463 pp.

Janssen, P. E. M., S. Abdalla, H. Hersbach, and J.-R. Bidlot, 2007: Error estimation of buoy, satellite, and model wave height data. J. Atmos. Oceanic Technol., 24, 1665-1677, doi:10.1175/ JTECH2069.1.

Keihm, S. J., M. A. Janssen, and C. S. Ruf, 1995: TOPEX/Poseidon Microwave Radiometer (TMR): III. Wet troposphere range correction algorithm and pre-launch error budget. IEEE Trans. Geosci. Remote Sens., 33, 147-161, doi:10.1109/36.368213.

- , and Coauthors, 2009: Ocean water vapor and cloud liquid water trends from 1992 to 2005 TOPEX Microwave Radiometer data. J. Geophys. Res., 114, D18101, doi:10.1029/ 2009JD012145.

Mieruch, S., S. Noël, H. Bovensmann, and J. P. Burrows, 2008: Analysis of global water vapour trends from satellite measurements in the visible spectral range. Atmos. Chem. Phys., 8 , 491-504, doi:10.5194/acp-8-491-2008.

Obligis, E., L. Eymard, N. Tran, S. Labroue, and P. Femenias, 2006: First three years of the microwave radiometer aboard Envisat: In-flight calibration, processing, and validation of the geophysical products. J. Atmos. Oceanic Technol., 23, 802-814, doi:10.1175/JTECH1878.1.

,-- , and -2007 : A new sidelobe correction algorithm for microwave radiometers: Application to the Envisat instrument. IEEE Trans. Geosci. Remote Sens., 45, 602-612, doi:10.1109/TGRS.2006.887165.

—, A. Rahmani, L. Eymard, S. Labroue, and E. Bronner, 2009: An improved retrieval algorithm for water vapor retrieval: Application to the Envisat Microwave Radiometer. IEEE Trans. Geosci. Remote Sens., 47, 3057-3064, doi:10.1109/ TGRS.2009.2020433. 
Parkinson, C. L., and D. J. Cavalieri, 2012: Antarctic sea ice variability and trends, 1979-2010. Cryosphere, 6, 871-880, doi:10.5194/ tc-6-871-2012.

Trenberth, K. E., J. Fasullo, and L. Smith, 2005: Trends and variability in column-integrated atmospheric water vapor. Climate Dyn., 24, 741-758, doi:10.1007/s00382-005-0017-4.

Wentz, F. J., and T. Meissner, 2007: Supplement 1: Algorithm theoretical basis document for AMSR-E ocean algorithms. RSS Tech. Rep. 051707, 6 pp.
C. Gentemann, and P. Ashcroft, 2003: On-orbit calibration of AMSR-E and the retrieval of ocean products. Extended Abstracts, 12th Conf. on Satellite Meteorology and Oceanography, Long Beach, CA, Amer. Meteor. Soc., P5.9. [Available online at https:// ams.confex.com/ams/annual2003/techprogram/paper_56760.htm.]

Zlotnicki, V., and S. Desai, 2004: Assessment of the Jason microwave radiometer's measurement of the wet tropospheric path delay using comparisons to SSM/I and TMI. Mar. Geod., 27, 241-253, doi:10.1080/01490410490465625. 